\title{
WestVirginiaUniversity
}

THE RESEARCH REPOSITORY @ WVU

Graduate Theses, Dissertations, and Problem Reports

2008

\section{Participation in Accelerated Reader programs and reading pursuit in 11th grade}

Heather E. Boucher

West Virginia University

Follow this and additional works at: https://researchrepository.wvu.edu/etd

\section{Recommended Citation}

Boucher, Heather E., "Participation in Accelerated Reader programs and reading pursuit in 11th grade" (2008). Graduate Theses, Dissertations, and Problem Reports. 2857.

https://researchrepository.wvu.edu/etd/2857

This Dissertation is protected by copyright and/or related rights. It has been brought to you by the The Research Repository @ WVU with permission from the rights-holder(s). You are free to use this Dissertation in any way that is permitted by the copyright and related rights legislation that applies to your use. For other uses you must obtain permission from the rights-holder(s) directly, unless additional rights are indicated by a Creative Commons license in the record and/ or on the work itself. This Dissertation has been accepted for inclusion in WVU Graduate Theses, Dissertations, and Problem Reports collection by an authorized administrator of The Research Repository @ WVU.

For more information, please contact researchrepository@mail.wvu.edu. 
PARTICIPATION IN ACCELERATED READER PROGRAMS AND READING

$$
\text { PURSUIT IN } 11^{\mathrm{TH}} \text { GRADE }
$$

Heather E. Boucher

Dissertation submitted to the College of Human Resources and Education at West Virginia University in partial fulfillment of the requirements for the degree of

\author{
DOCTOR OF EDUCATION \\ in \\ Curriculum and Instruction \\ Steven Rinehart, Ed.D., Chair \\ Ardeth Deay, Ph.D. \\ Joy Saab, Ed.D. \\ Douglas Smith, Ph.D., Litt. D. \\ Jaci Webb-Dempsey, Ph.D. \\ College of Human Resources and Education \\ Morgantown, West Virginia \\ 2008
}

Key Words: Accelerated Reader, Reading Attitude, Reading Pursuit, Reading Motivation

Copyright 2008 Heather E. Boucher 


\begin{abstract}
Participation in Accelerated Reader Programs and Reading Pursuit in $11^{\text {th }}$ Grade
\end{abstract}

Heather E. Boucher

Teachers and researchers continue to seek ways to build positive attitudes about reading and effective ways to promote robust reading interests. Some schools have implemented the reading software Accelerated Reader (AR) with these goals in mind. The purpose of the present study was to analyze the effects of long-term participation in the activities of AR on reading attitude and reading pursuit. Participants were 206 eleventh-grade students from the mid-Atlantic Region. The Estes Attitude Scale (Estes, 1969) and Title Recognition Test (Pavonetti, Brimmer, and Cipielewski, 2000) served as measures of reading attitude and reading pursuit, respectively. Data analyses indicated no effects for AR participation on these measures, regardless of participation duration. Ten percent of the students also participated in a follow-up conversational interview focusing on reading movitation and interests. Comments from AR students suggested that their reading pursuit during AR activities was linked to the program's extrinsic rewards. The AR students were also more likely to rate their reading ability by their AR grade equivalency scores, as they often referred to their scores when describing themselves as readers. 


\section{ACKNOWLEGEMENTS}

I wish to express my sincere gratitude to my disseration committee for encouraging me each step of the way. I would especially like to thank my advisor, Dr. Stephen Rinehart, for working with me despite the long distance between us, for guiding me through each step, for making time to advise and edit, and for helping pull everything together. I would also like to thank Dr. Ardeth Deay for helping make our doctoral group a reality and for driving hundreds of hours each year to provide courses in our locale. 


\section{DEDICATION}

This dissertation is dedicated to the people that I love most dearly:

Don, my husband of almost 20 years, who has faithfully encouraged me to pursue my dream and without whose computer skills I might not have finished.

Alyssa, Don, and Melanie, my children, who were not all around when I first started to pursue my master's degree. As you are considering what career paths to take, I hope that seeing your mother finally achieve her dream will enable you to broaden your horizons and realize that all things are possible.

Our parents, Clara Blair and the late S. Ray Blair, as well as Don and Marion Boucher, who encouraged and supported me along the way. I thank you for the example you have set for me and future generations. 


\section{TABLE OF CONTENTS}

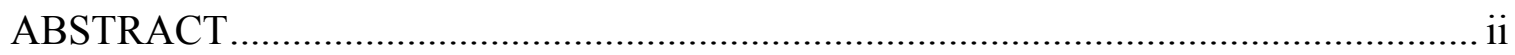

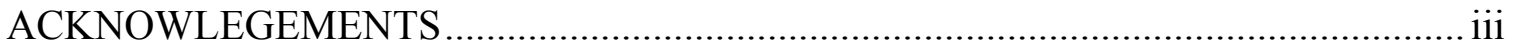

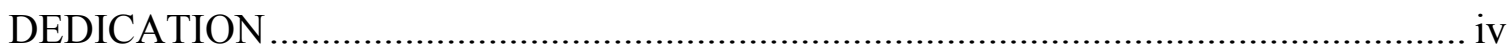

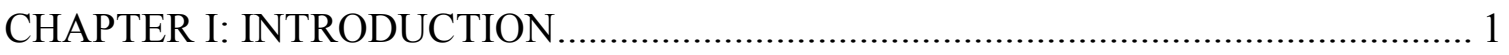

CHAPTER II: REVIEW OF RESEARCH AND RELATED LITERATURE ................. 5

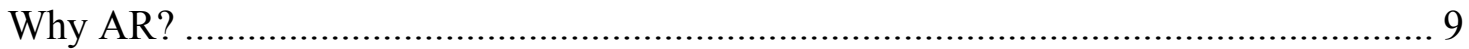

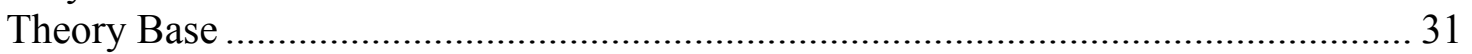

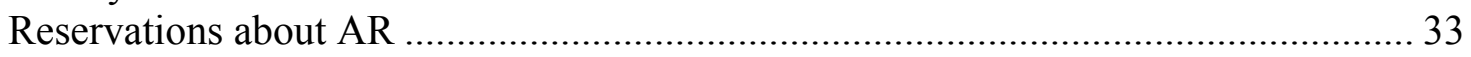

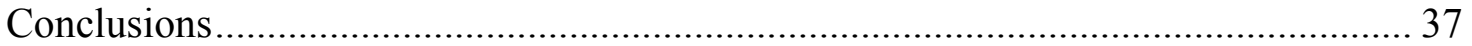

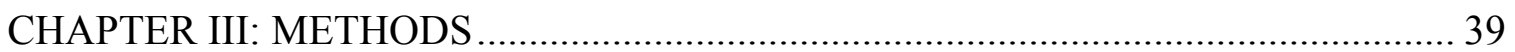

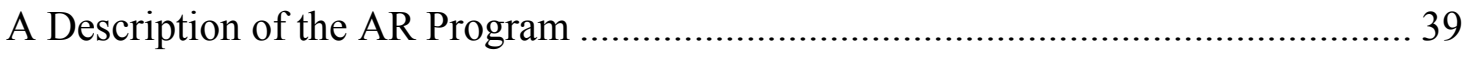

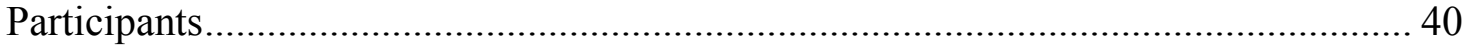

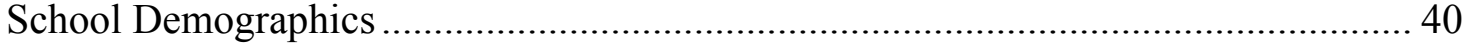

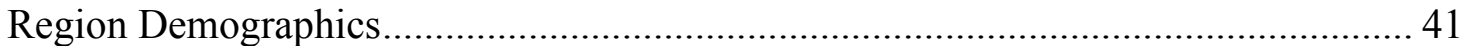

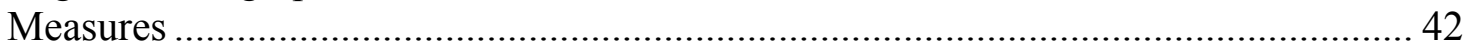

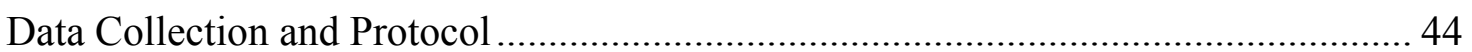

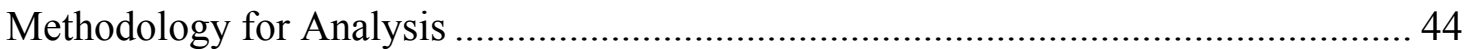

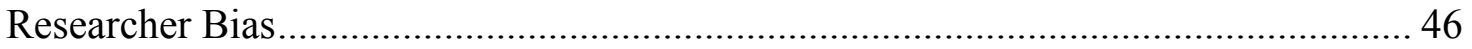

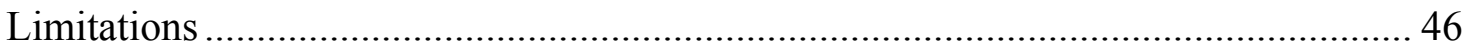

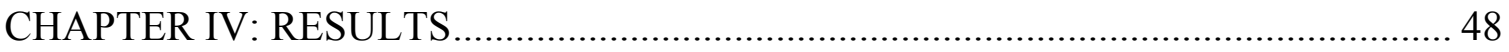

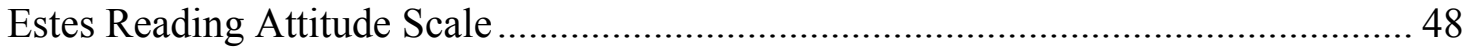

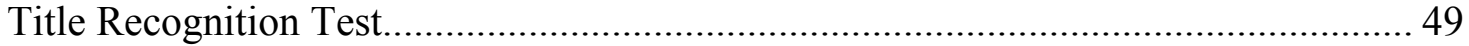

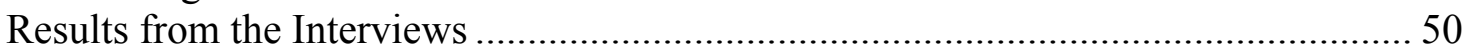

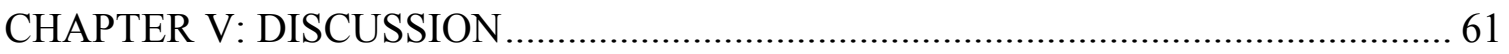

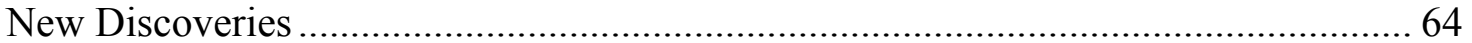

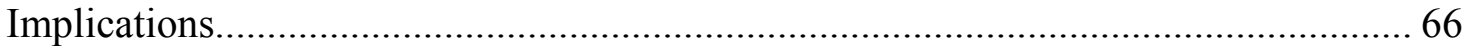

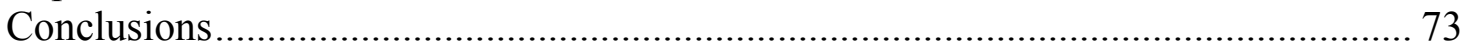

Recommendations for Future Work.................................................................... 76

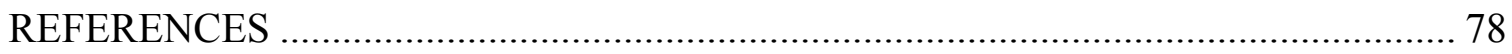

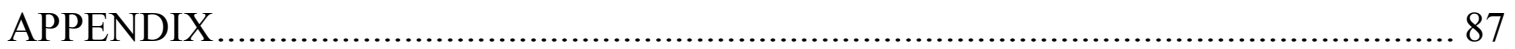

A: Estes Reading Attitude Scale ........................................................................ 87

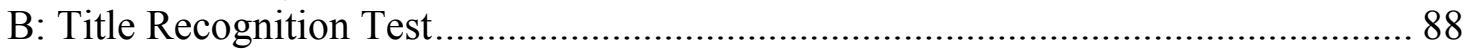

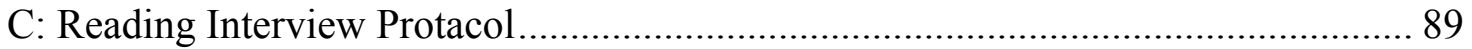

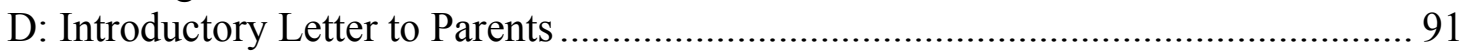




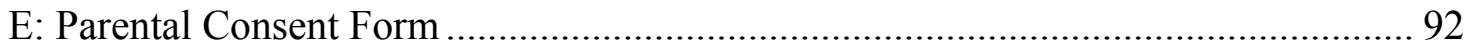

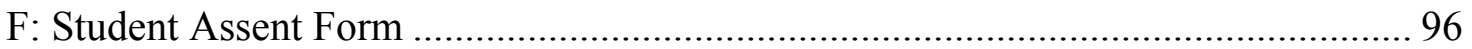

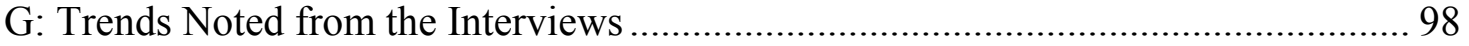

\section{LIST OF TABLES}

Table 1: Computer Programs and Websites Designed for Reading Instruction ................. 8

Table 2: Years in Accelerated Reader Versus Standardized Test Scores ....................... 16

Table 3: Pre- and Posttest Effects of Accelerated Reader Use ..................................... 24

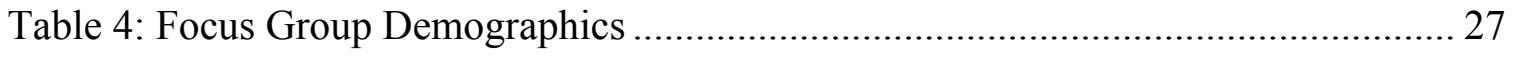

Table 5: Amount of Time Spent Reading and Reading Achievement of Fifth Graders (N

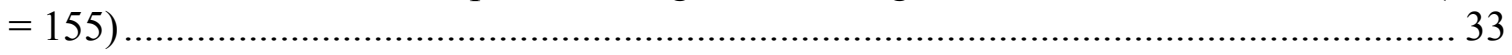

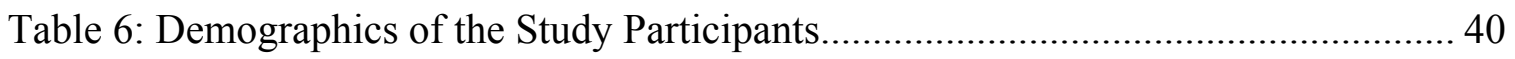

Table 7: Mean Estes Attitude Scale Scores ............................................................... 49

Table 8: Mean Title Recognition Test Scores......................................................... 50

Table 9: Demographics of the Interview Participants................................................. 52 


\section{CHAPTER I: INTRODUCTION}

Reading instruction is one of the primary goals of education and is a source of great concern throughout the country. It has rightly been said that "reading is more important than anything. Reading frees us from the here and now. It makes us human" (Keller, 2000, \39). This potential "humanizing" aspect of reading may fall short of its potential when it fails to reach everyone. Results of a National Adult Literacy Survey found that approximately 50 million adult Americans have only a minimal reading ability (Goodling, 2000). The National Right to Read Foundation has generated some alarming statistics: "Eighty-four percent of the 23,000 people who took an exam for entry-level jobs at New York Telephone in 1988 failed. More than half of Fortune 500 companies have become educators of last resort, with the cost of remedial employee training in the three R's reaching more than 300 million dollars a year" (Sweet, 1996, p. 2). The bottom line is that illiteracy and nonliteracy not only affect the population by limiting the shared "humanizing" literary experiences, but they also limit the job market for many.

The federal government has expressed its concerns with the status of public education repeatedly in the past years. The US Secretary of Education, Margaret Spellings stated that, "American students are losing significant ground in reading and math scores as they enter high school" (Aspey, Walsh, \& Yudof, 2005, p. 2). The government has repeatedly tried to "correct" and "better" the educational system with the enactment of different laws, with No Child Left Behind being a recent addition. In particular, Part B of this Act, known as Reading First, requires schools that receive some of the allocated $\$ 900$ million funds to adopt "comprehensive, scientifically-based reading materials" (Otaiba, Kosanovich-Grek, Torgesen, Hassler, \& Wahl, 2005, p. 380).

The importance of learning to read is reflected by the funds specifically allocated to this area. The proposed national budget for the year 2006 specifically set aside $\$ 250$ 
million in the education budget for high school reading, language arts, and math programs, and \$200 million for instituting a reading program to raise teenage students' reading abilities (Aspey, Walsh, \& Yodof, 2005). This proposed budget would raise the funds available to the Department of Education to $\$ 56$ billion. The importance of education to this administration is evident in that since his first election in 2000, President George W. Bush has increased the overall education budget by $\$ 13.8$ billion, which amounts to a $33 \%$ increase over that time period. In addition to funds being spent directly on education, it is estimated that six billion dollars are allocated to welfare and unemployment compensation due to illiteracy (Sweet, 1996).

Educational research also reflects the great public concern with education and literacy. There is a copious amount of research regarding reading theories, strategies, and programs. In fact, the International Reading Association reports that the subject of literacy is the focus of more than one thousand research papers each year (Sweet, 1996). This fervor to analyze reading strategies and programs has not ignored the more contemporary computer-enhanced reading programs. One of the more recent programs, the Accelerated Reader (AR) Program, which made its debut in the public market in 1986 and has since expanded to reach over 67,000 schools worldwide (Accelerated Reader website, renlearn.com.ar.overview), making it "the world's most popular reading management software" (Amazing Things Happen at Schools that Use Accelerated Reader, n.d. as cited in Pavonetti, Brimmer, Cipielewski, 2000, p. 4), has not missed the attention of educational researchers. There have been over thirty-one dissertations written examining the use of the AR program. The bulk of this research focused on the correlation of the AR program's use with reading achievement. Special groups (ESL, LEP, at-risk, and gifted students) have all been specifically examined as well as the use of the program in Grades K-8 and Grade 10. Most of this research concluded that AR has 
a significantly positive effect on reading comprehension scores, although the fact that many of the researchers had direct links to the Rennaisance Learning Corporation and relied on ex post facto correlational studies must be considered.

Three early studies, designed and carried out by the program's maker, similarly concluded that there was a strong positive correlation between accumulation of AR points (accrued through the use of the program) and increased standardized test scores (Paul, $1992 ; 1993 ; 1996)$. The bulk of research, both in the United States and overseas, leads to the same conclusion: Use of the AR program is correlated with increased standardized reading vocabulary and comprehension test results (Topping \& Fisher, 2001; Education Commission of the States, 1999).

Some educators are concerned, however, about the effects programs such as AR have on students. They worry that

...children who restrict themselves, or are restricted by outside forces, to books included in either AR or Electronic Bookshelf [now Reading Counts, a program similar to AR] will never encounter tried and true motivators such as love of reading; enjoyment of a certain genre, author, or series; and personal enjoyment. In the process, we may not only turn children off to school books, but may lose lifetime readers. (Carter, 1996, pp. 23-24)

The behaviorist motivational techniques that AR uses to "hook" children dangling prizes for earning AR points - are especially brought to question. Opponents of AR ask how student reading will be affected once the extrinsic rewards are discontinued. One study that examined whether AR students continued to read more than non-AR students after the program was discontinued found a negative impact. Fewer books were read by former AR students than by their non-AR peers (Pavonetti, Brimmer, \& Cipielewski, 2000). Other aspects of the program that have drawn criticism are the 
limited book selection, the methods the company uses to select books to put on their lists, the exclusion of poetry and highly visual texts, the use of detail-oriented multiple choice tests for the assessment of comprehension, and the lack of group discussions about books (Stevenson \& Camarata, 2000; Biggers, 2001; Pavonetti, Brimmer, \& Cipielewski, 2000; Chenoweth, 2001; Carter, 1996).

In light of the importance of motivation to the maintenance of any action and the questions being raised about the effects of the extrinsic rewards inherent in AR, the purpose of this study has been to analyze the relationship between AR participation and subsequent reading attitudes, motivation, and pursuit. Specifically, the study has posed these research questions:

1) What are the relationships between long-term participation in AR and subsequent reading attitude?

2) What are the relationships between long-term participation in AR and subsequent reading pursuit?

3) What do high school juniors have to say about reading motivation during a conversational interview? 


\section{CHAPTER II: REVIEW OF RESEARCH AND RELATED LITERATURE}

The Accelerated Reader (AR) program despite its international use today, had very inauspicious beginnings. A mother, who was a former school teacher, developed it because she wanted to find a way to motivate her children to read more, both in quantity and quality (Paul, Topping, \& Schnick, 1995; NW Regional Educational Laboratory, 2004). Judi Paul, its creator, noted that most in-school and summer reading programs only tracked the number of books read, which often drew children to the easiest and smallest books they could find to meet the desired quota. To combat this tendency, Mrs. Paul assigned books points based on the Fry Readability Formula (Paul, et al., 1995). Mrs. Paul constructed multiple choice tests to verify that her children had read the books. Reading the books and passing the tests were the criteria for earning points, which could be used for tangible rewards. To aid with the tracking of the tests and point system, Terry Paul who was a computer programmer, designed a computer application to incorporate his wife's ideas (Paul, et al., 1995). Friends and a parochial school requested and used this computer program, and it was finally developed into the commercially produced reading management software program that is known today as AR (Paul et al., 1995).

\section{Available Computer Programs for Reading}

Since the advent of the computer, there have been several computer programs written aimed at increasing literacy. Computers can be an asset in the educational realm: They can aid in diagnosing and remedying reading difficulties and can offer individualized, self-paced instruction with immediate feedback (Ediger, 2002). Research

that compared seven instructional strategies used with mildly disabled children found that computer-assisted instruction and direct instruction using Holt reading materials 
correlated with the most significant, and nearly identical, gains (Marston, Deno, Kim, Diment, \& Rogers, 1995).

Many of the computer reading programs available at this time are aimed directly at instructional techniques, and offer tutorials, drill and practice, diagnosis and remediation, simulation, and gaming scenarios (Ediger, 2002). Many of them are directly geared at various age groups. Among these are:

- Waterford Early Reading Program (1995): This program combines individualized computer instruction and classroom instruction for Pre-Kindergarten (Pre-K) through Grade 3. By the end of 1998, 1003 schools in 38 districts had adopted this program in the US. Results of research on this program are mixed, with a program school that was directly studied receiving a lower vocabulary score on the Iowa Test of Basic Skills (ITBS) after 1 year (Walker, 1999d).

- SuccessMaker (1995-6): This program focuses on comprehension, vocabulary, phonics, and writing using units of study to complement reading programs for Pre-K through Grade 8 . It had been used by 16,000 schools nationwide as of 1999. SuccessMaker boasts special features for bilingual and special needs students. It costs \$121-201 per student per year (Walker, 1999c).

- Breakthrough to Literacy (1981): This program, which is published by the Wright Group, aims to increase phonemic awareness and vocabulary for students in Pre-K through Grade 2. It is used by 40,000 children in 36 states with a classroom cost of $\$ 12,500$, which covers software, big books, take-home books, writing journals, and training (Walker, 1999b).

- ClickN'Read: This program, which is published by ClickN'Kids, Inc., focuses on developing phonemic awareness, word recognition, and decoding skills for 
students in Pre-K through Grade 5. One concern with this program is that it is hard for students who struggle with typing. It costs between \$20-29 per student depending on the quantity ordered (Lafferty, 2005).

- Primary Reading: This program, which is published by Lexia Learning Systems, Inc., focuses on increasing phonemic awareness, sight words, vocabulary, and comprehension for students in Grades K through 5. It costs $\$ 159$ for a stand alone license or $\$ 500$ for network capability (Lafferty, 2005).

- Thinking Reader: This program, which is published by Tom Snyder Productions, Inc., focuses on improving comprehension, fluency, reading strategies, vocabulary, and literature appreciation for Grades 5 through 8, but has a severely limited library of only 9 titles. This program costs $\$ 500$ for 10 student licenses (Lafferty, 2005).

- Reading Assistant: Published by Soliloquy Learning Inc. This program focuses on developing fluency, comprehension, and vocabulary for Grades 1 through 5. Its initial library includes fourteen selections of fiction, nonfiction, poetry, with additional selections available separately. This program costs $\$ 229$ for a stand alone license or $\$ 2000$ for a network license (Lafferty, 2005).

Besides these programs that are designed primarily for use in schools, there are many programs and websites available for personal use (Lafferty, 2005). Some of these are included on Table 1. 
Table 1: Computer Programs and Websites Designed for Reading Instruction

\begin{tabular}{|c|c|c|}
\hline Program/Website Name & Internet Address & Program Focus \\
\hline Achievement Technologies & www.achievementtech.com & $\begin{array}{l}\text { Reading, Writing, Language, } \\
\text { Math, Science }\end{array}$ \\
\hline AutoSkill International & www.autoskill.com & $\begin{array}{l}\text { Fluency, Automaticity, Reading } \\
\text { Skills, Phonics, Decoding, } \\
\text { Comprehension }\end{array}$ \\
\hline BrightStar & www.getbrightstar.com & Reaing (Dyslexic Students) \\
\hline Cognitive Concepts & www.earobics.com & $\begin{array}{l}\text { Phonemic Awareness, } \\
\text { Decoding, Spelling, Writing }\end{array}$ \\
\hline CompassLearning & www.compasslearning.com & $\begin{array}{l}\text { Phonics, Fluency, Vocabulary, } \\
\text { Comprehension }\end{array}$ \\
\hline Crick Software & www.cricksoft.com & Vocabulary, Word Identification \\
\hline Don Johnston & www.donjohnston.com & $\begin{array}{l}\text { Phonics, Comprehension, } \\
\text { Fluency, Study Skills }\end{array}$ \\
\hline Failure Free Readig & $\underline{\text { www.failurefree.com }}$ & $\begin{array}{l}\text { Learning Sight Words (Deaf } \\
\text { Students) }\end{array}$ \\
\hline Headsprout & www.headsprout.com & Reading (Grades K-2) \\
\hline IntelliTools & www.intellitools.com & $\begin{array}{l}\text { Reading Skills, Comprehension } \\
\text { (Grade 3) }\end{array}$ \\
\hline Kurzweil Educational Systems & www.kurzweiledu.com & $\begin{array}{l}\text { Scanning Programs (Blind or } \\
\text { Dyslexic Students) }\end{array}$ \\
\hline Kutoka Interactive & www.kutoka.com & Reading, Math (Grades K-2) \\
\hline LeapFrog SchoolHouse & www.leapfrogschoolhouse.com & $\begin{array}{l}\text { Phonics, Reading } \\
\text { Comprehension (Grades K-5) }\end{array}$ \\
\hline OpenBook Learning & www.openbooklearning.com & $\begin{array}{l}\text { Reading (English as a Second } \\
\text { Language Learners) }\end{array}$ \\
\hline PLATO Learning & www.plato.com & Reading Skills \\
\hline Publication International & www.pilbooks.com & Electronic Books \\
\hline Reading A-Z & www.readinga-z.com & Online Books \\
\hline Riverdeep & www.riverdeep.net & Phonics, Reading Skills \\
\hline Scientific Learning & www.scilearn.com & $\begin{array}{l}\text { Reading (Students with } \\
\text { Memory, Attention, Procession } \\
\text { Problems) }\end{array}$ \\
\hline Siboney Learning Group & www.orchardsoftware.com & Skills \\
\hline StepWare & www.stepware.com & Reading Speed, Comprehension \\
\hline
\end{tabular}

The computer program that is the most similar to AR is Reading Counts (Chenoweth, 2001), formerly Electronic Bookshelf, which is owned by Scholastic. Since being acquired by Scholastic, Reading Counts has become a more powerful presence in public education, and is currently used in thousands of public schools nationwide (Chenoweth, 2001). Like AR, Reading Counts is a motivational reading program designed to supplement the classroom instruction. It also assigns book levels and offers the flexibility of allowing teachers to add their own tests to the system for book selections that are not included. Reading Counts places more emphasis on earning points and 
tangible awards than AR and advises strengthening community relationships to obtain prizes for the program (Carter, 1996; Chenoweth, 2001).

Why AR?

Why have many school districts adopted AR and continue to use it 20 years after its conception? As stated previously, AR has been repeatedly demonstrated to have a significant correlation with rising vocabulary and comprehension scores on standardized test and with amount of books read, which is of great interest to schools.

The AR program additionally offers schools the largest selection of leveled books, with more than 100,000 book quizzes available as of 2006 (Renaissance Learning, Inc., 2006). These book selections encompass “good children's literature” (Stevenson \& Camarata, 2000, p. 8) and include both fiction and nonfiction selections.

The AR program's philosophy is that students are motivated to read by the selfselection of books and the extrinsic rewards of tangible prizes, which can be won by the accumulation of points. As students read more at increasingly challenging levels, they build reading skills and enjoy reading more. The company boasts that "students who never read before suddenly become voracious readers after they experience success with Accelerated Reader" (Swanson, 2000 as cited in Pavonetti, Brimmer, Cipielewski, 2000, p. 4). The public testimonies that substantiate this claim recruit more and more schools to jump on the AR bandwagon. As one librarian stated in a journal article, "Our experience... has found that AR does encourage independent reading in high school students, and that students can be motivated to read with computerized reading management programs such as AR" (Moyer, 2006).

The AR program is furthermore an easily implemented program that monitors both reading level and quantity read (Holmes \& Brown, 2003) and gives immediate feedback on both of these aspects as well as each student's comprehension level, as 
assessed by the computerized test. The ease of implementation and monitoring is critical, especially because AR is designed to supplement, not replace, schools' reading programs (Education Commision of the States, 1999; NW Regional Educational Laboratories, 2004).

Whether it is the ease of use, the research that supports its use, or its base in theory, AR is flourishing and gaining ground in both private and public schools throughout the country as well as the world.

\section{Effects of AR on Achievement}

\section{Renaissance Learning Corporation Research}

Just 6 years after its influx onto the public market, the Institute of Academic Excellence (the research arm of Renaissance Learning Corporation, which is the parent company of AR) launched the first of three major studies to examine the effects of AR on achievement. In the first of these studies, Paul (1992) surveyed 63 schools throughout the US that were using AR. Paul compared amount of reading practice, measured by the amount of AR points accumulated, with reading growth, measured by standardized test scores. He found that the accumulation of AR points correlated with increases in standardized test scores for all but the high achievement group. It should be noted when considering this study that it lacked a control group and relied on the voluntary completion of surveys. The second major study of the AR program (Paul, 1993) was a similar correlational study. In it, Paul compared the amount of reading practice, again measured by the amount of AR points accumulated, with achievement, this time as measured by pre- and posttest results of standardized tests. Paul found that there were significant correlations between the amount of reading practice and standardized test scores (both reading and math subsections). Although this study was much larger than the first ( $N=10,124$ students in Grades 1-9 from 136 schools), there could be a similar 
bias in the data set, because Paul did not address the selection criteria. Additionally, neither study took into consideration some key issues in the AR program and school in general such as amount and types of rewards, teacher effectiveness, school demographics, teacher interaction throughout the AR program, or amount of Sustained Silent Reading time allotted per day. A third study (Paul, 1996), again used surveys to collect data from schools using AR. Out of 13,000 schools sampled, 2,193 completed and returned their surveys, giving data on 659,214 students in Grades K through 12. These surveys yielded some interesting data regarding reading practices in general: They indicated that time set aside in the school day for reading practice increases from kindergarten through Grade 6, then declines. Notably, reading activities in Grades 4 and 5 averaged the most allotted practice time, whereas reading activity in Grade 9 dropped back to the amount given in kindergarten. Interestingly, small schools averaged twice as much reading time as large schools. Paul found this reading time was crucial: Students scoring in the top 5\% on standardized tests read 144 times as much as those scoring in the bottom 5\%. As for his main purpose in conducting the study, Paul found a $64 \%$ increase in reading practice for schools using AR for 4 or more years as compared to schools using the program for only 1 year.

Subsequent studies continued to find correlations between use of AR and achievement as measured on standardized test scores. Peak and Dewalt (1994) conducted a study based in the Gaston County School System in North Carolina. They matched two schools in this district, whose major difference was the use of AR, and analyzed 3 years' results (ex post facto data Grades 3, 6, and 8) from the California achievement test -reading subtest for the ninth-graders from both schools' college preparation programs. They found that the AR group averaged a 15.3 point gain from third grade to sixth grade as compared to a 10.2 point gain for the control group in the same time period. They 
found an even wider gap from the sixth to the eighth grade: a gain of 13.2 points for the AR group versus a gain of 5.5 points for the control group. The stepwise multiple regression analysis used to examine the effects of AR found a significant effect.

In another early study that involved data collected by the Tennessee Value-Added Assessment System, which is the largest "longitudinally merged database of student achievement in the US," Paul, Swanson, Zhang, and Hehenberger (1997) obtained standardized test scores for 62,739 students in Grades 2 through 8 from the Tennessee Comprehensive Assessment Program for the entire state of Tennessee for the 1995-1996 school year. They divided these scores into three categories: Renaissance school (purchased AR prior to September 1995), Transition school (purchased AR between September 1995 and May 1997), and Non-Renaissance school (did not purchase AR). In all grades analyzed, the number of years that schools used AR positively corresponded to increased standardized test scores.

Vollands, Topping, and Evans (1999) conducted two parallel studies to examine the correlation between use of AR and achievement. In Project A, the AR group consisted of 27 students who had 15 minutes of Sustained Silent Reader per day for the first 5 weeks at which time it was increased to 30 minutes per day for the final 6 months of the study as well as having 30 minutes of oral reading time per day. The control group, which consisted of 12 students, had 30 minutes of Sustained Silent Reading per day but no oral reading. The achievement level of the AR group was measured by the accumulation of AR Points. Vollands et al. measured the achievement level of the control group by assigning point values that were earned based on written feedback for each book. In Project B, the AR group, which consisted of 24 eleven-year-old students, was allotted 15 minutes of Sustained Silent Reading four times a week for 3 months and then 20-30 minutes of Sustained Silent Reading four times a week for the final 3 months. 
The control group, which consisted of 26 ten-year-old students, had 15 minutes of Sustained Silent Reading per day as well as group oral reading, reading level group instruction, public display of the ten novels the students were allowed to choose to read from, and homework assignments for each book chapter read. Vollands et al. found that in both sections of this study, the AR group showed more improvement based on the results of standardized achievement pre- and posttests. It should be noted that the two groups in Project B were not matched well. The AR group was one year older, had more males than females (14:10 as compared to $10: 16$ for the control), scored lower than the control group on the pretest, and did not have the same "work ethic" as the control group. Additionally the control group was severely limited in book choice, as they could only choose from ten novels.

Holmes and Brown (2003) used data from the ITBS for 2000 along with scores from The Georgia Criterion-Referenced Competency Test (CRCT) for 2001 and 2002, as well as data from the Standardized Test for Assessment of Reading (STAR) Test, which is a computerized cloze test used to determine students grade equivalency scores and assign AR reading levels and target points. They identified two schools that were identified as "model Renaissance schools," which indicates that they not only implement AR and Renaissance Math, but have also received training from the Renaissance Company. They also identified two contrast schools, which used AR to a limited extent. Schools were matched in terms of percentage free and reduced lunch, percentage minority students, and geographic location. An Analysis of Covariants (ANCOVA) test design was utilized since contrast, not control, schools were used with the ITBS scores as the covariants, and the 2001 and 2002 CRCT scores as the dependent variables. Holmes and Brown analyzed and compared the scores from the contrast and treatment schools. Their data indicated that the schools identified as model Renaissance schools made more 
significant gains than the contrast schools the first year of the study and increased those gains through the second year of the study. The STAR scores were similarly contrasted, and for the most part, the data indicated that use of AR correlated with increased ITBS scores with the exception of Grade 4.

Still another study compared the change in percentage rank based on the 1999 and 2000 Texas Assessment of Academic Skills (TAAS) scores. In this study, Smith and Clark (2001) obtained and compared both the TAAS scores and the STAR test scores to coincide with the 1999 implementation of the AR and Renaissance Math programs. They found that the implementation and use of the Renaissance Reading and Math Programs correlated with increased test scores on both assessments and that the number of students scoring in the lowest two quartiles made more significant gains over the 2 years than those scoring in the upper two quartiles.

Topping and Fisher (2001) continued to examine the effects of AR use on achievement as measured by standardized test scores in their first international study, where they selected thirteen schools from England and Scotland from a list of volunteer schools. They provided these schools with free training in AR, 350 free AR books, and a full software package. Topping and Fisher collected scores from two group-administered reading tests that are commonly used in the United Kingdom, the Primary Reading Test and the Group Reading Test II 6-14, on a pre-, interim, and post-test basis using two parallel forms of the tests over a seven-month period (September 1999-April 2000) and used the STAR test results to confirm the rise in scores over the year of implementation. They concluded from the data collected that the use of AR resulted in increased standardized test scores, with the most significant gains being made by socioeconomically disadvantaged students. 
Independent Peer-Reviewed Research

As the program gained both national and international acceptance, a few

independent researchers became interested in examining its effects for themselves. These studies have more clout than the studies previously mentioned because they were both conducted by researchers who have no financial or personal ties to the Renaissance Learning Corporation, which manufactures and sells the AR program.

Jones and Coody (2001) conducted a study over the course of 5 years, from 19941999 in an early elementary school that had implemented AR in November 1994. They obtained and analyzed the data from the Iowa Test of Basic Skills (ITBS) for each year and concluded that the use of AR over the 5 years correlated with extremely high gains on the Iowa Test of Basic Skills: First grade rose from the $53^{\text {rd }}$ to the $88^{\text {th }}$ percentile, and second grade rose from the $51^{\text {st }}$ to the $75^{\text {th }}$ percentile.

In another study, which is notable due to its focus on lower income minority students who were failing (the school in the study was put on Academic Alert II by the state in 1997), Fine (2000) compared Stanford 9 Test scores for Grades 3-5 both by grade level and by percentage of students identified as Alert, Caution, and Clear by virtue of their test scores. Fine's data indicated that use of AR; which included buying new AR books and quizzes, having Renaissance Learning train the librarian, putting up an AR Point Club Wall of Fame, utilizing many rewards based on AR points, setting up tutoring programs where fourth and fifth graders helped students in kindergarten through second grade with reading and taking the AR tests, and having parents sign the computer generated AR reports; correlated with a significant rise in standardized test scores. After the first year of implementation the school was removed from the Academic Alert II status. 
Graduate Level Research

As the AR program gained prominence in American schools, it became the subject of several dissertations and masters theses. Many of these, like the previously mentioned studies, examined how AR points correlated to pre- and posttest scores on standardized tests and attitude scales.

Gibson (2002) studied at-risk black eighth graders at Etta Middle School in Mississippi. This school was listed as "deficient" by the state due to low student performance on standardized tests for previous years. The entire student population received free lunch. Gibson concluded that the longer the AR program was used, the lower the standardized test scores dropped, as shown on Table 2.

Table 2: Years in Accelerated Reader Versus Standardized Test Scores

\begin{tabular}{|c|c|c|c|c|}
\hline $\begin{array}{c}\text { SUBGROUP } \\
\text { (YEARS IN }\end{array}$ & NUMBER & MEAN & STANDARD & STATISTICAL \\
AR) & & & DEVIATION & SIGNIFICANCE \\
\hline 0 & 3 & 33.78 & 6.24 & - \\
\hline 1 & 17 & 33.59 & 9.52 & 0.1783 \\
\hline 2 & 17 & 22.65 & 8.13 & 0.0439 \\
\hline 3 & 15 & 19.58 & 6.73 & 0.3194 \\
\hline
\end{tabular}

However, there were some serious concerns with the study: The experiemental group in this study was not random, but included the entire eighth grade class at the school. Moreover, this group of eighth graders had a high mobility rate, which resulted in vast differences in the sample numbers each year. The students in the AR program did not receive other reading instruction; AR appeared to be used as the sole reading 
program. Results may have also been skewed due to the use of two different tests in the study: the ITBS in 1999, and the Terra Nova Test in 2000 and 2001.

Knapik (2002) examined the measured gains and losses on the Stanford 9 reading and language arts subtests over a 3-year period starting September 1998 and ending May 2001. Two schools were matched for this study in an urban Los Angeles County School District as per socioeconomic, ethnic, and language status. These schools were within 5 miles from each other. The schools used the same basal curriculum and similar instructional procedures. Knapik found that the use of AR correlated with significant positive gains for the Total Language scores from the Stanford 9, but the gains were not statistically significant for the individual subtests.

Hagerman (2003) similarly conducted a quasi-experimental pre-/posttest design focused on sixth graders from two schools chosen from a large suburban school district outside the metropolitan Portland area. Hagerman matched the schools based on socioeconomic factors, students receiving special services, ethnic backgrounds, and teacher preparation. There were two main differences between the schools. The control school set aside 20 minutes for silent reading each day and had novel studies as part of each reading class. The AR school mandated 30 minutes set aside for silent reading each day and had no novel stuies in reading class. Hagerman found that AR students' reading increased 22.0 minutes on average per day, whereas the control students's reading decreased an average of 3.6 minutes per day, and therefore concluded that AR positively impacted reading habits. He also concluded that AR positively affected comprehansion from his analysis of the gains measured between pre- and posttest results on the Tests of Reading Comprehension: A Method for Assessing the Understanding of Written Language-3. 
Steele (2003) conducted a causal comparative study of 142 second graders at Florence Elementary School (Mississippi). The group was $52 \%$ male, $48 \%$ female; 77 $\%$ white, $22 \%$ black, $1 \%$ Asian, and $1 \%$ other. Twenty-eight percent of the sample received free or reduced lunch. In 1995, six years prior to Steele's study, the school had purchased and implemented AR for the third grade. In January 1999, the school expanded the AR program to include the second grade at Florence Elementary. The library was accessible each day in the 30 minutes preceding instruction in addition to the regular classroom library times, which were scheduled twice a week. There were 2,800 AR titles available for checkout. The study began in August 2001, when all study participants took the STAR pretest. Over the next 8 months, the 142 students in the study took 26,686 AR quizzes and passed all but 946 of them. The students additionally kept logs of the books they read, which documented the titles, AR levels, and point values of the books read. The teachers recorded the number of points earned on each quiz and sent these logs home to be signed an average of three times each week. After the 8 month study period, the students were retested using STAR. T-tests were run on the pre- and posttest scores using both grade equivalent and scaled scores. Steele found that AR use had a positive significant effect on both the grade equivalent and scaled scores and that the relative growth was greater for the males than females.

Schreiber (2004) conducted a case study of 8 fifth-graders from a northern Delaware (K-5) school within a district that was semi-urban and had a $60 \%$ poverty level, and a $10 \%$ ESL rate. This school, where Schreiber was the AR coordinator, had implemented AR in 1999 in an effort to raise reading achievement and test scores. The school received Renaissance training, set aside a schoolwide Sustained Silent Reading time, and directed students to read books at their instructional reading level as indicated by the STAR test. After three years' use of AR, the school was awarded the Model of 
Excellence in Education Award due to raised test scores. Schreiber chose the participants randomly within two categories: Four students that had scored on or above grade level on the Delaware Student Testing Program in third grade (2 years previously) and four that had scored below grade level. She refined these categories further, so that each category had two students that met their AR goal and two that did not in their third grade year. He interviewed each student in the study, observated their classrooms, and additionally interviewed their parents, teachers, and the school administrators. Schreiber concluded that use of AR positively affects reading performance, time spent reading positively affects reading performance, AR helps all students regardless of their reading ability, and that adhering to AR guidelines and "buying into" the program increases its success. She posited that the success of this school was linked directly to the adoption of Renaissance recommended practices and the enthusiastic support of teachers, parents, and students.

Bullock (2005) studied 114 third, fourth, and fifth graders to examine the effects of AR on reading achievement. The school that was the focus of this experiment was 91 $\%$ white, $4 \%$ Hispanic, $2 \%$ black, and $3 \%$ other, and $61 \%$ of the student body received free or reduced lunch. Bullock randomly assigned students to two groups: an AR group and a control group. Both groups received 90 minutes of Sustained Silent Reading and 30 minutes of library time per week. The AR group was assigned books at their instructional reading level and took book quizzes. The control group updated book charts as they read books. Based on the pre- and posttest results from this experiment, Bullock concluded that there were not significant differences found on the STAR reading or the Dynamic Indicators of Basic Early Literacy Skills pre- and posttests for either group. Kobel (2005), Walker (2005), and Dickerson (2005) all researched the effect of AR on different grade levels of the same large, urban school district in Delaware. Kobel 
used a quasi-experimental approach to compare pre- and posttest scores on the STAR Test and on the Delaware State Performance Assessment. The AR group consisted of 87 tenth-graders, while the Control group consisted of 30 tenth graders. The data from the STAR test indicated that the Control group declined slightly while the AR group increased by an average of 1.5 years when grade equivalency scores were compared. Similarly, the AR group improved their scores on the Delaware State Performance Assessment, while the Control group declined slightly. Walker examined a group of 103 eighth-grade students who had used AR for at least one year between their fifth and eighth grade years and found a significant positive difference for the STAR tests: increases in AR points correlated positively to increases in test scores. However, he found no correlation between AR points and the scores on the Delaware State Performance Assessment scores. Dickerson (2005) explored data from the same school system, but examined the correlation between accumulation of AR points and factors that colleges use in their student selection criteria, such as grade point averages, number of academic classes with A or B averages, and verbal portion of the Scholastic Aptitude Test (SAT). Participants were the 112 students that graduated from Milford High School in 2004, had been in attendance there for all four years of high school, and had taken the SAT test by Spring 2004. Students that had been retained, were in special education classes, or did not have AR data for all four years were excluded from the study. Ex post facto data on the grades, grade point averages, and test scores were obtained, and Walker concluded from this data that accumulation of AR points had a significant positive correlation with each of these college entrance criteria.

Knox (1996) compared changes in reading achievement as measured by the Stanford Achievement Test-8 in the twelfth largest school district in the United States. This school district had a $32 \%$ minority rate, a $67 \%$ mobility rate, and $72 \%$ of its students 
qualified for free or reduced cost lunches. The study used a 2 (grade) x 2 (group) x 2 (time) mixed design. Knox matched the 77 fourth and fifth grade students after rankordering them based on their pretest independent level score on the Spache Diagnostic Reading Scale. Knox assigned these students to either an AR group or a group that used a teacher-initiated reading program, wherein the students answered in-depth comprehension questions about each book and drew an illustration for each book using computer graphics. Knox found no significant difference between the use of AR and the teacher-initiated reading program on reading achievement as measured by the reading vocabulary and comprehension subtests of the Stanford Achievement Test-8, found a positive non-significant effect on the vocabulary subtest of the Spache Diagnostic Reading Scale for the AR group, and found a large positive effect on the comprehension subtest of the Spache Diagnostic Reading Scale for all the fourth graders involved in this study regardless of their treatment group.

Holman (1998) randomly sampled the population of fourth and fifth graders attending Early County (Georgia) Elementary School to examine the correlation between use of AR and standardized test scores. Early County Elementary School was described as a rural, socioeconomically disadvantaged school, with $67 \%$ of the students receiving free or reduced lunches, $31.4 \%$ of the county residents living below the poverty level, $12.5 \%$ of the residents receiving Aid to Families with Dependent Children, $45.9 \%$ of the county (at least 25 years old) having less than a high school education, and $22.6 \%$ having less than a ninth grade education. The school population was $54.9 \%$ white, $44.1 \%$ black, and $1 \%$ other. This school had not purchased the STAR diagnostic test, so individual teachers assessed student reading abilities and assigned student AR levels. Prizes were a prominent part of the AR program, ranging from stickers and bookmarks, to trips to an ice cream store and video coupons. In addition, yearly awards were given for the most 
AR points earned individually and for the highest average reading level attained by a homeroom for each grade level. Holman used the results of the ITBS (March 1996 and 1997) from the sample of 170 fourth and fifth graders as the pre- and posttest data and found no significant statistical difference between accumulation of AR points and reading comprehension gains using this data nor a significant statistical difference between preand posttest scores. However, Holman did not reject the premise that AR positively impacts students' reading comprehension, and speculated that the use of standardized tests to measure reading achievement was flawed because standardized tests are standardized at each grade level, not by reading ability, so they do not measure gains made by low-ability students adequately and also because standardized tests measure reading ability or reading aptitude more than being a measure of reading achievement.

Harrell (1999) compared the degree of teacher involvement with the AR program, the points earned by students in their respective classes, and reading level gains. This study compared two matched third grade classrooms, one with high teacher involvement in the AR program, and one where AR was used independently with little teacher involvement. Holman found a significant difference in the number of AR tests passed and points earned between the classes, found a $19 \%$ increase in library book circulation, but did not find a significant difference in reading level gains as assessed by the STAR diagnostic test.

Bork (1999) examined AR effects on reading level scores as measured by STAR in two parochial schools in a Midwestern city $(N=241)$. Students at these schools were predominantly white and were academically above average. On the STAR pretest, administered in mid-January or February, the students averaged 1.9 years above their grade level on the STAR test. At the end of the study, only 38 students were reading below grade level, and 24 of these had earned low AR points. Eleven students that 
scored below grade level on the pretest scored above grade level on the posttest. Bork found a moderate positive correlation between AR points and reading level gains as measured by the STAR test. Bork noted that some "very good and avid" readers did not participate in AR as anticipated, but this was not delved into.

Kunz (1999) sent requests for information on use of AR and Illinois Goals Assessment Program test scores to "hundreds" of schools in Illinois, with 500 schools responding. Kunz found that AR use correlated with a positive significant effect on average reading scores on the Illinois Goals Assessment Program. He concluded:

This program [AR] succeeds because people love to read, and the children are empowered to read the literature they love the most. The passion for literature is passed on to the children from the program; the children become readers because they see a book as an opportunity to learn, to earn points, and to be recognized. The program itself increases self-esteem and develops a love for reading. (pp. 84-85)

Howard (1999) examined the effects AR use in seven Title I schools in an urban area of southeast Virginia. These schools had at least $80 \%$ of the student bodies receiving free or reduced lunch and were predominately black. There was no control group for this study. The 755 third, fourth, and fifth grade students in the study took the Gates-MacGinitie Tests of Reading, Form L as pre- and post-tests. Howard classified AR usage by the amount of points accumulated over the year: low (0-20), average (2174), and high (over 75). In the pretest, $75 \%$ of the participants scored below grade level in both comprehension and vocabulary. In the posttest, the percentage of students below grade level significantly decreased, as shown in Table 3 
Table 3: Pre- and Posttest Effects of Accelerated Reader Use

\begin{tabular}{|c|c|c|c|c|c|c|c|}
\hline & & & GRADE & $\begin{array}{c}\text { VOCAB. } \\
\text { (PRETEST) }\end{array}$ & $\begin{array}{c}\text { VOCAB. } \\
\text { (POSTTEST) }\end{array}$ & $\begin{array}{c}\text { COMP. } \\
\text { (PRETEST) }\end{array}$ & $\begin{array}{c}\text { COMP. } \\
\text { (POSTTEST) }\end{array}$ \\
\hline \multirow{3}{*}{ 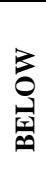 } & \multirow{3}{*}{$\begin{array}{l}\text { 滥 } \\
\text { 晃 }\end{array}$} & & 3 & 81 & 36 & 83 & 43 \\
\hline & & 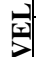 & 4 & 76 & 52 & 81 & 48 \\
\hline & & & 5 & 77 & 68 & 77 & 59 \\
\hline \multirow{3}{*}{$\begin{array}{l}\text { ố } \\
\text { ż }\end{array}$} & \multirow{3}{*}{ 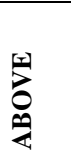 } & & 3 & 19 & 64 & 17 & 57 \\
\hline & & $\overrightarrow{\mathrm{a}}$ & 4 & 24 & 48 & 19 & 52 \\
\hline & & & 5 & 23 & 32 & 23 & 41 \\
\hline
\end{tabular}

Students with low AR usage had an average growth of 0.73 grade equivalent years, students with average AR usage had an average growth of 1.52 years, and those with high AR usage had an average growth of 2.24 years on the Gates-MacGinitie Test of Reading. Without intervention, one year's growth was expected over the year-long course of the study. The Univariate Analysis of Variance run on the resulting data indicated a statistically significant effect for AR: As participation in AR increased, the mean score differences increased.

Morse (1999) used a pre/posttest design to examine the correlation between accumulation of AR points and reading ability as measured by the STAR test, with a sample of 60 students in Grades 1-3, whose STAR pretests indicated that their instructional reading level was Grade 2. Morse placed these students into three categories at the end of the study by their accumulated AR points: low (less than 20 points), mid (20-49 points), and high (more than 50 points) and found that the high group averaged a 1.46 increase in their grade equivalency score and the low group averaged an 0.84 increase in their grade equivalency score. It should be noted that this school wholeheartedly embraced the AR program. It conducted four inservice trainings on AR for its staff prior to school opening, it purchased AR handbooks for each teacher, it 
mandated Sustained Silent Reading throughout the school each day, and it offered many rewards including certificates, incentive tokens, and public recognition.

Griffin (2000) studied the correlation between AR use and reading achievement as measured by pre- and posttest scores on the North Carolina End-of-Grade Tests for Grades 3-8. The school district involved in the study was described as a small rural district that was predominantly white (93\% white, 3\% black, 3\% Hispanic, and 1\% other). Griffin examined 134 teachers to assess each teacher's degree of program implementation. Based on the responses, the surveys were divided into two groups: high and low implementation. Griffin found that the degree of program implementation had a significant effect for Grade 3 only. Griffin went on to compare the pre- and post test scores from this district that implemented AR with the scores for the rest of the state and found that there were significant statistical differences between the district's and the state's reading growth as measured by the change in reading scores in Grades 3, 4, 7, and 8. Griffin also found that Grade 3 had the largest standardized growth estimate (SGE $=$ 1.20). The other grades had small to moderate standardized growth estimates (SGE = 0.34 to 0.54 ). The standardized growth estimate was found by subtracting the average pretest score from the average posttest score and dividing it by the standard deviation for each grade level. Griffin concluded that AR had the most effect on lower grade levels.

\section{Effects of AR on Attitude}

There have been few studies on the effects of AR on attitude. One of these was part of a study conducted for the Renaissance Learning Corporation (Smith \& Clark, 2001), and the others were all graduate studies (Rogers, 2000; Watts, 2004; Sims, 2002; Eliason, 2005). These studies have produced mixed findings: Two of the studies concluded that AR led to increased reading attitudes (Smith \& Clark, 2001; Sims, 2002), two concluded that AR led to declining reading attitudes (Watts, 2004; Eliason, 2005) 
and one study (Rogers, 2000) found that AR increased students' perceptions of themselves as readers. Two of the studies (Smith \& Clark, 2001; Watts, 2004) used surveys of students, teachers, and/or parents to arrive at their data, two of the studies used reading attitude tests (Eliason, 2005; Sims, 2002), and one study (Rogers, 2000) used an interview approach.

Rogers (2000) examined the "perceived impact" of AR on a high-achieving Georgia elementary school that served Grades 3-5. This school had been recognized by the state as a Georgia Dream School based on its standardized test scores and as an Accelerated Reader Model School by the Institute for Academic Excellence. It had a heterogeneous population, with $68 \%$ white, $30 \%$ black, and $2 \%$ other; $46 \%$ of the school population lived below poverty level; $9 \%$ were gifted; and $17 \%$ were receiving special education services. The school required all students to participate in $\mathrm{AR}$, and all but the four new teachers completed training in AR. The school set aside thirty minutes each day for Sustained Silent Reading and gave rewards including candy, special privileges, and a schoolwide rewards party and school store every six weeks. Rogers interviewed seven students in Grade 5 who were chosen randomly from each of the seven fifth grade rooms and interviewed their respective teachers. She also held three focus groups, which were organized based on academic achievement as shown in Table 4. 
Table 4: Focus Group Demographics

\begin{tabular}{|c|l|}
\hline ACADEMIC ACHIEVEMENT LEVEL & \multicolumn{1}{|c|}{ GROUP DEMOGRAPHICS } \\
\hline Gifted & White: 2 girls, 3 boys: \\
\cline { 2 - 2 } & Black: 2 girls, 1 boy \\
\hline Regular Classroom (No special services) & White: 3 girls, 2 boys \\
\cline { 2 - 2 } & Black: 1 girl, 2 boys \\
\hline Title I & White: 2 girls, 3 boys \\
\cline { 2 - 2 } & Black: 2 girls, 1 boy \\
\hline
\end{tabular}

The majority of the interviews and the focus group data revealed that the students felt that they were more and better readers since participating in the AR program. All the teachers interviewed agreed that AR was successful to a degree in boosting reading achievement and that it was an efficient way of keeping organized data on all the students. Students, teachers, and the principal reported that AR resulted in students reading more, allowed freedom of choice, was a good management program, aided in controlling student behavior, allowed teachers to work with different ability levels in the same class, developed students' self-confidence, allowed students to read a wide variety of literature, and set individual reading goals. They also noted that AR exerted pressure on students to reach the goals, led to students eventually "burning out" of the program, extinguished classroom discussions about books, rated nonfiction books lower than fiction books, and led some students to become "point accumulators." The gifted focus group had the most complaints about the AR program. They had their gifted class during the Sustained Silent Reading time and felt that the punishments they received for not meeting their goals, such as losing recess, were unfair. Many of these students were tired 
of the AR program and did not like the school rule that any book checked out from the library must be read in its entirety and tested on. One student commented that "'Getting points is the main thing"” (p. 67), and a gifted student frankly stated that “"Accelerated Reader takes the fun out of reading"' (p. 69). Rogers concluded that low-functioning students were more responsive to the extrinsic rewards offered.

Watts (2004) surveyed 74 junior high students (Grades 7, 8, and 9), along with their parents and teachers in a small, semi-rural, upper middle class school in Pierce County, Washington to examine the effects AR had on reading motivation. Sixty-seven of the students were white, 5 Asian, 1 black, and 1 Native American. The ratio between girls and boys was 46:28. All but 9 of the students were reading at least one full year above grade level. This school invested in the AR program heavily: it bought 3742 quizzes and the program for over $\$ 10,000$, allotted 15 minutes of Sustained Silent Reading per day in addition to 30 minutes of Sustained Silent Reading in language arts classes per week, assigned 3 hours of reading per week as homework, and mandated that $10 \%$ of the reading grade be based on AR scores. Averaging the Likert scale results gave no clear patterns; however, color-coding the responses by the frequency of response, indicated some patterns. There was strong agreement that the STAR test correctly identified the students' reading ability based on the students' views of themselves as readers and on their standardized comprehension skills. However, the students, over half of the parents, and the teachers indicated that AR had negative effects on student motivation to read. The heavy requirement to read each night was criticized as was the lack of available AR books on the students' level. Teachers likewise complained of frustration with the AR program, although four of the five teachers surveyed stated that the use of AR increased students' independent reading. As a result of the first survey, students were allowed to "graduate" from the AR program if they scored at the highest 
grade equivalent level (12.9) on the STAR test. The choice of books was also expanded to non-AR books and students were allowed to write their own tests on these books. A second survey indicated that $65 \%$ of the respondents liked the modifications to the AR program, although the groups (teachers, parents, and students) agreed that the use of AR had negative effects on motivation to read.

Sims (2002) set up a quasi-experimental study to look at the effects of Sustained Silent Reading and AR on student attitudes and achievement with low-achieving eighth graders. The school Sims chose to conduct her study in was $80 \%$ black and $20 \%$ white, with $65 \%$ of the student population receiving free lunches and $25 \%$ receiving reduced lunches. The school scored in the thirty-eighth percentile for reading on the ITBS. The eighth grade was set up in three clusters, with each cluster being further separated into four heterogeneous classes. Each cluster was assigned a different treatment group: AR in addition to 15 minutes Sustained Silent Reading per day, Sustained Silent Reading for 15 minutes per day only, and Regular Instruction (Control). Sims gave pre- and posttests at both ends of the 4-month study: the STAR test to measure reading achievement, and the Estes Attitude Survey to measure reading attitude. It was found that there was a statistically significant positive effect for the AR group in relation to both achievement and attitude.

Smith and Clark (2001), as part of their study on achievement and attitude for the Renaissance Learning Corporation, surveyed teachers early in the school year regarding their use of and satisfaction with Accelerated Reader. Of the 239 teachers that responded, 122 indicated that they used the AR program in 1999-2000. Eighty percent of the respondents reported that they were satisfied with the AR program, and noted that they recognized changes in attitudes toward reading, improvements in socially and economically disadvantaged students' reading skills, ease of individualizing instruction, 
and increased parent involvement in the schools. Smith and Clark additionally conducted group interviews with administration, librarians, and parents but did not elaborate on the data they gathered in this manner.

Eliason (2005) studied 128 third, fourth, and fifth graders in the largest urban area in Lane County, Oregon to determine differences in pre- and post- test results of the Elementary Reading Attitude Survey for students participating in the AR program, and those participating in Sustained Silent Reading with reading logs. Eliason randomly selected the study's participants after blocking for grade level, reading teacher, and reading ability as assessed by teacher rank ordering. One constraint in this study was the amount of AR books available to students: Only 1,504 books out of the 12,832 books in the library collection were AR books. Eliason found that almost all the groups (AR and Sustained Silent Reading Control Group at all reading levels) declined in reading attitude as measured by the Elementary Reading Attitude Survey.

\section{Effects of AR on Reading Pursuit}

One independent peer-reviewed study specifically examined the effects of AR on individuals' reading pursuit. Pavonetti, Brimmer, and Cipielewski (2000) gave a Title Recognition Test (TRT) to 1771 seventh graders in one ex-urban and two suburban schools. The Title Recognition Test consisted of twenty-six actual book titles and sixteen foils intermixed. The students took the tests in a controlled group setting, and Pavonetti et al. scored the tests by counting the number of actual titles identified and subtracting the number of foils identified. Then, they divided the tests into two categories: tests from students that had previously used AR and tests from students who had not used AR. The t-test results comparing these two groups indicated a decrease in the amount of titles recognized by the AR group. 


\section{Effects of AR on English as Second Language Learners}

Castillo (2002) conducted a 14-week study on the correlation of AR use with reading achievement as measured on the STAR test in a pre/posttest design for her master's thesis. The subjects in this study were 15 third-grade English language learners who were enrolled in a fulltime bilingual program in the Los Angeles Unified School District. The school was $85 \%$ Hispanic, 7\% black, 4\% white, 2\% Filipino, $1 \%$ Pacific Islander, and 2\% Asian; 50\% of the student body were English language learners; and $86 \%$ lived below the poverty level. One student's score in this study skewed the results drastically (that child fell from grade equivalent level 4.0 to 2.4). When that score was disregarded, the results showed a statistically significant improvement in reading scores from the time of AR implementation. Castillo stated that, "Certainly, however, the use of Accelerated Reader did not decrease the student's reading level" (p. 18), but did not comment further on the one atypical score. Castillo concluded that "Accelerated Reader is a program that has clearly resulted in increased student achievement" (p. 21).

Theory Base

The AR program is predominately based on the theory that increasing the quantity and simultaneously increasing the difficulty of what is read will improve reading vocabulary and comprehension, which in turn will increase motivation to read (Holmes \& Brown, 2003). Indeed, William Sanders of the University of Tennessee concluded that the monitoring of books read and the continual "nudging up" in difficulty level, as opposed to simply increasing reading quantity without monitoring the reading level, increases reading comprehension (Chenoweth, 2001). This is very much in agreement with Lev Vygotsky's (1987) theory that points out the importance of instruction taking place in the zone of proximal development. 
Moreover, this theory is substantiated by the fact that children scoring in the top $10 \%$ on standardized tests read more per year, especially recreationally, than those that score in the lowest 10\% (Holmes \& Brown, 2003; Pavonetti, Brimmer, \& Cipielewski, 2000). The creators of AR cite this research in their promotional materials, saying, "When time is set aside for independent reading and monitoring, reading achievement improves" (Vollards, 1996 as cited in Scott, 1999, pp. 22-23; cf. Hamilton, 1997; Institute of Academic Excellence, 1997; Paul, 1996). For this reason, the AR program recommends that 60 minutes be set aside for reading each school day.

In this day and age, when middle school students typically watch between three and six hours of television per day but read less than 1 hour during that same time period (Lesesne, 1991), the need for increasing the amount of time spent reading is critical, since the amount of time spent reading builds reading skills. "The value of reading ability lies in its use rather than its possession" (Estes, 1971, p. 135). When children do not read, they lose the opportunity to hone their skills as readers. However, even though it is widely agreed that students need to spend more time reading (See Table 5), much of classroom time is devoted to workbook and skill sheet activities (Anderson, et al., 1985). 
Table 5: Amount of Time Spent Reading and Reading Achievement of Fifth Graders ( $N=$ 155)

\begin{tabular}{|c|c|c|}
\hline $\begin{array}{c}\text { PERCENTILE } \\
\text { RANK }\end{array}$ & $\begin{array}{c}\text { MINUTES OF TEXT } \\
\text { READING PER DAY }\end{array}$ & $\begin{array}{c}\text { ESTIMATED NUMBER } \\
\text { OF WORDS READ PER } \\
\text { YEAR }\end{array}$ \\
\hline 98 & 90.7 & $4,733,000$ \\
\hline 90 & 40.4 & $2,357,000$ \\
\hline 70 & 21.7 & $1,168,000$ \\
\hline 50 & 12.9 & 601,000 \\
\hline 20 & 3.1 & 134,000 \\
\hline 10 & 1.6 & 51,000 \\
\hline
\end{tabular}

(from Anderson et al., 1985, Table 3)

Besides increasing the amount of time spent reading individually, which directly correlates to increased reading scores (McQuillan, 1998), the AR program offers students something that strictly adhering to a basal reading series does not: self-selection of what is read, which research indicates correlates with increased motivation (Angeletti, 1991; Lesesne, 1991).

\section{Reservations about AR}

However, there are critics of the AR program that point to deficiencies in this theory base and in the inadequacy of the research. Some of these critics specifically question the depth of the research on AR. G. Reid Lyon, the chief of the National Institute of Child Health and Human Development's child development and behavior branch stated, "The absence of well-designed research on these specific programs [AR and Reading Counts] tells the story" (Chenoweth, 2001, p. 2). They note that most of the 
research that has been touted to draw schools to purchase and use the program has been conducted by individuals or groups that have a direct interest in the company (Education Commission of the States, 1999). Interestingly, neither AR nor Reading Counts have met the federal standards for "programs that have been proven, with independent research to be effective" (Chenoweth, 2001, p. 2, emphasis added).

The Renaissance Learning Corporation and AR tout the effect AR use has on standardized test scores almost exclusively. The company-sponsored studies that base their conclusions on standardized test scores indicate that use of AR consistently correlates with higher test scores. Even the independent studies that examine AR's effect on achievement are mostly in agreement with this finding. With a large number of similar studies and a high degree of agreement between studies, it would seem at least to the casual observer that this finding is highly conclusive. However, it must be stressed that the correlational nature of the studies as well as the relationship between many of the researchers and Renaissance Learning pose questions concerning this conclusion. Chenoweth's (2001) warning that the AR program has not met the federal standards for scientifically based reading research must be given due consideration when examining the program.

Moreover, unless the sole goal of education in general and school in particular is to raise standardized test scores, there are other areas to consider, such as reading motivation and attitude. Pavonetti, Brimmer, and Cipielewski’s (2000) study took a step in this direction by examining if use of AR correlated to the amount of books read by using Title Recognition Tests; and Smith and Clark's (2001), Sims's (2002), Rogers's (2000), Eliason's (2005), andWatts's (2004) studies paved the way in studying the effects of AR on attitude, but here too, the studies were limited. 
Some critics despair not of the lack of research, but of the very components of the program, such as the extrinsic reward system, which they question is appropriate or truly "builds lifetime readers" as the program touts. Sharon Coatney, the ex-president of the American Association of School Librarians, states, “I just don't like to treat children like dogs. It's very Pavlovian" (Chenoweth, 2001, p. 4). Moreover, as with Pavlov's research, some educators wonder if continual use of the program will ultimately lead to extinction of the very goal of this program, lifelong reading: "Do Reading Counts and Accelerated Reader improve children's reading ability and develop a lifelong thirst for a good book? Or do their low-level quizzes and prizes turn reading into an empty contest and actually discourage reading?" (Chenoweth, 2001, p. 1). When the push for a specified number of points is the foremost goal, books may well be chosen for their point value instead of their content or interest. Betty Carter, the associate professor in the School of Library and Information Studies at Texas Woman's University warns, "Reward readers may never discover solutions for their blocked motivation if they succeed in looking like readers and acting like readers rather than becoming readers" (Carter, 1996, p. 25). Thus, the rewards that purportedly encourage children to become lifelong readers, may ultimately discourage that very aim. Furthermore, when book selection is limited, either by the number of books that have a desirous point level, by the quantity of leveled books a given library has, or by the number of tests that a school owns, students lose the opportunity to discover what they really like - what they might pick up for themselves outside of the reading program (Angeletti, 1991).

Another area that is brought into question is the computerized testing that students complete to give evidence that they have actually read the book, comprehended it, and earn points. These tests focus on detailed factual questions that a reader supposedly could only know if they actually read the book. However, it has been shown that it is 
possible for an adult to pass such a test with flying colors without having read a given book; or conversely, to fail a test after having read a book (Chenoweth, 2001). Many critics question the use of low-level questions that require the reader to read efferently in order to remember details no matter what type of book is read. Rosenblatt points out that part of reading is choosing what stance to take: efferent or non-aesthetic (to acquire information, solve a problem, or find out how to do something), aesthetic (for pleasure) or a combination or both (Rosenblatt, 1994). When students' pleasure reading is subjected to tests that measure the detailed information they have remembered from the book, it forces the students to read at least somewhat efferently or risk failing the test, no matter what the genre of the book. It has been recommended that aesthetic responses should come before efferent responses, both in discussions and on tests and that aesthetic responses are crucial for a student's development as a lifelong reader (Rosenblatt, 1994; Beers, 1996). Angeletti agrees and offers suggestions for writing higher-level thinking questions to accompany books (1991). Carter (1996) is likewise concerned with the use of standardized computerized tests, which limit students' personal opinions and responses.

With all the focus on the amount of books read and passing the computerized tests, some are asking, "Do they [the students] read because they love to or because they have to?" (Chenoweth, 2001, p. 2).

Is Accelerated Reader helping schools encourage lifelong readers, or is this entire program a misuse of computer technology that could better be used elsewhere? Is Accelerated Reader's use of computer technology to track what is read, deliver and score factual tests, and maintain a progress log actually akin to "deploying an army to kill an ant”? (Carter, 1996, p. 25) 


\section{Conclusions}

Ensuring that all inhabitants of this nation learn to read is without a doubt a top priority to parents, educators, and the country as a whole. It might well be asked if a tool such as AR, which seems to improve quantity read and standardized test scores, should be applauded and adopted simply for these reasons. However, the long-term effects of using a reward-based program such as $\mathrm{AR}$, as well as its focus on limited genres and detailed tests, must be weighed in the balance. It seems reasonable to find out what happens after students discontinue the AR program before any final decisions are made.

With the amount of information about the AR program available, it is reasonable to ask why another study would be beneficial. Certainly, it appears from the studies that the use of AR has a fairly consistent significant correlation to rising standardized test scores at least in the short term. However, as previously noted, the correlational nature of the previous studies, their narrow focus on test scores, as well as the relationship of many of the researchers to Renaissance Learning call into question the reliability of this conclusion. Moreover, there still seems to be the question of whether AR, which advertises itself as a program that will "instill a lifelong love of reading in all...students and help them achieve reading success" (Accelerated Reader website, emphasis added), actually has this effect after the program is terminated. For this reason, I analyzed the relationship between AR participation and subsequent reading attitudes and pursuit. Specifically, the present study examined the research questions:

1) What are the relationships between long-term participation in AR and subsequent reading attitude? 
2) What are the relationships between long-term participation in AR and subsequent reading pursuit?

3) What do high school juniors have to say about reading motivation during a conversational interview? 


\section{CHAPTER III: METHODS}

The focus of this study was to examine the long-term effects of Accelerated Reader (AR), which is a computerized method of tracking the quantity and difficulty of books read with the goal of increasing reading motivation, on subsequent reading attitude and reading pursuit. Juniors from two matched high schools served as the participants for this study. Analysis involved both quantitative and qualitative methods. The Estes Attitude Scale was used to measure reading attitudes. The Title Recognition Test allowed for comparison of reading pursuit between the groups. In addition, an adaptation of the Motivation to Read Profile: Conversational Interview was used to obtain more specific information and insight into both areas. This section fully describes the participants and methods.

\section{A Description of the AR Program}

The AR program is a computerized reading program that was designed as a motivational tool to develop "lifelong readers." It tracks reading quantity and difficulty of books read. Students using AR first take a STAR reading test to determine their grade equivalency scores and target point levels that they are to achieve. Then, they are directed to choose books that match that score and take computerized comprehension tests on the books. The students receive points based on the difficulty and length of the books read, which is adjusted for their scores on the comprehension tests. Once students reach their target point level, they are often rewarded with prizes and grades. If the target point levels are not met, they might receive negative consequences. 


\section{Participants}

The participants of this study were juniors from two high schools (School A and School B). The samples from both schools were well-matched in terms of number of participants as well as the gender and racial proportions of the samples, as shown in Table 6. Both samples were over $90 \%$ white and at least $60 \%$ female. However, the samples were quite unmatched as far as English level. It must be noted that School A did not offer Advanced Placement English to juniors during the year this study was conducted, while School B had two Advanced Placement Classes. School B also had more Honors English classes than School A, and School A offered General English courses, while School B did not.

Table 6: Demographics of the Study Participants

\begin{tabular}{|c|c|c|c|c|c|}
\hline & $\mathrm{N}$ & Gender & Race & English Level & Years of AR \\
\hline School A & 101 & $\begin{array}{l}\text { Male: } 33 \\
\text { Female: } 67 \\
\text { Unknown: } 1\end{array}$ & $\begin{array}{l}\text { White: } 92 \\
\text { Black: } 3 \\
\text { Hispanic: } 3 \\
\text { Other: } 2 \\
\text { Unknown: } 1\end{array}$ & $\begin{array}{l}\text { Advanced Placement: } 0 \\
\text { Honors: } 26 \\
\text { College Prep: } 66 \\
\text { General: } 9\end{array}$ & $\begin{array}{l}0: 11 \\
1: 4 \\
2: 12 \\
3: 56 \\
4+: 16 \\
\text { Unknown: } 2\end{array}$ \\
\hline School B & 105 & $\begin{array}{l}\text { Male: } 42 \\
\text { Female: } 63\end{array}$ & $\begin{array}{l}\text { White: } 97 \\
\text { Black: } 2 \\
\text { Hispanic: } 2 \\
\text { Other: } 4\end{array}$ & $\begin{array}{l}\text { Advanced Placement: } 32 \\
\text { Honors: } 41 \\
\text { College Prep: } 32 \\
\text { General: } 0\end{array}$ & $\begin{array}{l}\text { 0: } 97 \\
1: 2 \\
2: 1 \\
3: 4 \\
4+: 1\end{array}$ \\
\hline
\end{tabular}

\section{School Demographics}

School $\mathrm{A}$ is located in a rural mid-Atlantic region that is home to many commuters to a growing metropolitan area. At the time of the study, School A was operating with a building across the street dedicated solely to the ninth grade until a new high school could be finished and opened. As of 2004, School A, including the ninth 
grade complex, housed 2,121 students. Of these, $87.4 \%$ were white, $8.5 \%$ black, $3.2 \%$ Hispanic, 0.7\% Asian/Pacific Islander, and 0.3\% American Indian/Alaska Native, with $24.8 \%$ receiving free or reduced lunches.

School B is located 20.5 miles northwest of School A. Like School A, it is also in a rural area and is home to many commuters. School B housed 1,489 students as of 2004 . Of these $93.8 \%$ were white, $3.5 \%$ black, $2.1 \%$ Hispanic, and $0.5 \%$ Asian/Pacific Islander, with $25 \%$ receiving free or reduced lunches.

\section{Region Demographics}

This study was conducted in two neighboring counties in the mid-Atlantic region. Both counties are classified as rural, but are quickly becoming bedroom communities to a nearby city. The population of the first county, where School A is located, grew from 42,190 to 49,206 from 2000 to 2005 . The average yearly household income was $\$ 48,567$ in 2003 , above the state average of $\$ 32,967$. The county has a small minority population, with $95.2 \%$ of the population classified as white. A reported $16 \%$ of its residents live below the poverty level (US Census Website), and $29.89 \%$ of students qualify for the free and reduced lunch program (Standard \& Poors, 2006). The county school system, which served 7,874 students in the 2005-2006 school year (Standard \& Poors, 2006) adopted the AR program in 2001 when the three county middle schools were created. In addition to these three middle schools, the AR program is used by at least three elementary schools, had been used at one point by two additional elementary schools, and was available for use at the county's ninth grade complex.

The population of the second county, where School B is located, grew from 75,905 to 93,394 from 2000 to 2005 . The average yearly household income for this county was $\$ 43,301$ in 2003 . Like the previous county described, this county has a small minority population, with $92.7 \%$ of the population classified as white; $11.6 \%$ of the 
population live below the poverty level (US Census Website); and $38.46 \%$ of students are eligible for the free and reduced lunch program (Standard \& Poors, 2006). The county's school system, which served 15,624 students during the 2005-2006 school year (Standard \& Poors, 2006), does not use the AR program in its middle schools or high schools.

Measures

\section{Estes Attitude Scale}

The Estes Reading Attitude Scale is a quantitative method of measuring individuals' attitudes toward reading. The scale uses a series of twenty statements to assess both positive and negative reading attitudes, such as the first statement in the scale: "Reading is for learning but not for enjoyment" (Estes, 1971). Participants respond to these statements using a five-point Likert scale ranging from strongly agree to strongly disagree. The reliability of the scale was measured as .96 for Grades 7-12 (.92 for Grades 3-6), with a «.001 degree of significance using the split-half method with 283 heterogeneous students in Grades 3 through 12 in 1969 (Estes, 1971). This measure was chosen due to its high reliability and its focus on a breadth of reading attitudes.

\section{Title Recognition Test}

The Title Recognition Test (TRT) is an indicator of the amount of individual exposure to print. In the TRT, participants marked only the titles that they recognized as books from a list of actual books interspersed with fictitious titles. The TRT has been found to correlate well with daily activity diaries and activity preference questionnaires in "provid[ing] a reasonably reliable and valid measure of reading experience" (Allen, Cipielewski, \& Stanovich, 1992). The benefits of utilizing a TRT as opposed to an activity log or diary include the amount of time required to collect the data, its ease of use, the clarity of the directions, and the simplicity of obtaining data from all students, no matter their reading ability or organizational skills, which makes it a prime tool for use 
with already busy juniors. Additional advantages are that false reports, whereby participants cite what they think the researcher desires, are eliminated, and the consequences of guessing are eliminated by the presence of the foils. The disadvantages of the TRT are that it only indicates the amount of exposure to print relative to other participants and does not indicate the amount of time spent reading (minutes) or the types of books read (genres preferred, reading level, or number of words read). The TRT was originally used to assess adults' exposure to print, until a new TRT that included items for children was created and tested in 1992 with a sample of 63 private school fifth-grade students to find its correlation with other types of reading habit assessments. Scoring involved subtracting the number of the foils checked from the number of the actual titles checked, $\mathrm{M}=.586, \mathrm{SD}=.183$ with a split-half (odd/even) reliability of .84 . Since the TRT was tested with students in Grades 5-7, and the current study's participants were eleventh graders, the version created by Pavonetti, Brimmer, and Cipielewski (2000) was expanded to include books that were awarded the Michael L. Printz Award, given for "excellence in young adult literature" and the Young Adult Library Services Association's yearly lists of teens' top ten books (see Appendix B).

\section{Motivation to Read Profile: Conversational Interview}

Interviews of approximately $10 \%$ of the sample population provided useful insights from individuals' points-of view that could not be gained by a solely quantitative study, because using this method enabled the participants to more freely and completely express their opinions about the topics at hand. The Motivation to Read Profile: Conversational Interview (Gambrell, Palmer, Codling, \& Mazzoni, 1996) served as a template for the interview protocol, because it focuses on reading motivation, perceptions of selves as readers, and students' value of reading. Since this study focused on the effects of AR on subsequent reading attitude and pursuit, questions were added to delve 
specifically into how reading habits changed with advancing grades as well as students' perceptions of AR. The interviews were conducted in the faculty lounge at School A and in the school library at School B during the school day on the same day that the two other measures were given. The interviews were recoded using a digital tape recorder, and they were transcribed using Dragon Naturally Speaking software, which gave the basic framework that was used to refine the transcription process manually.

\section{Data Collection and Protocol}

Following approval from the Internal Review Board and the two high school principals, letters detailing the study and seeking participants were sent home with the junior class. Students turned in permission forms in each English class, at which time they took the Estes Attitude Scale and the Title Recognition Test. After the students finished, they immediately turned in both measures. I sorted the permision slips, selecting an interview group at random, without replacement, that was equal to $10 \%$ of the total sample and that was balanced for gender.

The Estes Attitude Test, the Title Recognition Test, and the random interviews were conducted at the students' respective high schools during their English classes on four separate days. Students completed all of the written measures in their normal English classes. The students chosen for the interview section were interviewed during their English period immediately after they had finished the Estes Attitude Scale and the Title Recognition Test. The interviews were given in the faculty lounge at School A and in the school library at School B. All interviews were digitally taped and transcribed using Dragon Naturally Speaking software.

\section{Methodology for Analysis}

The quantitative data were analyzed using Statistical Package for the Social Sciences (SPSS v11). Frequency graphs, histograms and t-tests allowed for comparison of the data 
from the two high schools. Analysis of Univariates allowed for the analysis of the effects of AR participation on reading attitude and pursuit. The number of years that a student participated in AR was the independent variable, and the scores obtained from the Estes Reading Attitude Scale and the number of titles recognized on the Title Recognition Test were the dependent variables. If a significant effect was found, $r^{2}$ was run using a 0.05 significance level to identify the size of the effect.

All data were analyzed according to the tenets of Grounded Theory, which “emphasizes steps and procedures for connecting induction and deduction through the constant comparison method, comparing research sites, doing theoretical sampling, and testing emergent concepts with additional fieldwork" (Patton, 2002, p. 125). The data were triangulated using mixed methods to measure reading attitude and pursuit.

I constantly and vigilantly compared the data from the interviews with the goal of detecting patterns from the data through coding the data and analyzing the answers. After making sure that the transcribed text was in agreement with the recorded narrative, I laid the scripts from each interview side-by-side so that the particular answers to each question could be read and the common themes that emerged from the answers could be discovered and analyzed. As each question was examined in this way, I recorded the key words for each answer in a table in order to aid in finding patterns. I organized the data gathered from the interviews based on the questions asked and the issues that the answers addressed (Patton, 2002). In this way, thus coding the answers (see Appendix G, Trends Found in Interview Data for the complete table of data patterns) to ensure that the data table was complete and correct, I reviewed the interviews on two other separate occasions in a similar fashion and analyzed the data carefully and repeatedly in order to "build" theory from the data with care taken not to use the data to fit a presupposed theory (Patton, 2002). The question, "What theory emerges from systematic comparative 
analysis and is grounded in fieldwork so as to explain what has been and is observed?" (Patton, 2002, p. 133), served as the basis for data comparison and analysis.

\section{Researcher Bias}

I first became aware of the AR program in 1999 when it was being implemented at the school where I was teaching. Recently, it has again come to my attention, as two of my children are using the program. Consequently, I have heard both positive and negative comments regarding the program from my children's perspectives. Casual discussions with the school librarian have also brought out the beneficial and detrimental effects of AR as our school expands the program to include additional grade levels. This was the impetus for examining this program in particular, to find out how it works, what its goals are, and how well it accomplishes them.

\section{Limitations}

This study involved juniors from two high schools from the mid-Atlantic region. This area has historically been a rural region, but it has quickly grown into a bedroom community to a nearby city. This study can only be directly attributed to this study group.

The generalizability of this study is restricted by the following limitations:

1. Only juniors of two high schools were included in the study.

2. Only two high schools from the same immediate area were included.

3. The vast majority of the subjects that were included in this study were white, and approximately $60 \%$ were female.

4. Participants filled out their tests and gave interviews in the school building during the course of the school day.

5. Only 206 students participated in the study. 
6. The study did not take into account socioeconomic factors, home life, or differences in reading curricula.

7. This study was not a longitudinal study and did not follow the students from elementary years, when AR was not used, through middle school years, when AR was used, to high school years, after the program had been discontinued. 


\section{CHAPTER IV: RESULTS}

The research questions for this study focused on the long-term effects of participation in Accelerated Reader (AR) on reading attitude as measured by the Estes Reading Attitude Scale and on reading pursuit as measured by performance on the Title Recognition Test. A follow-up interview with some of the participants allowed for additional exploration of reading motivation. These results are now presented.

\section{Estes Reading Attitude Scale}

All participants in this study took the Estes Reading Attitude Scale; however, two of the participants at School A turned in incomplete Attitude Scales, so those scores were excluded. The Estes Reading Attitude Scale measures reading attitudes by quantifying individual's reactions to statements about reading. Scores over 60 indicate a positive attitude toward reading; scores under 60 indicate a negative attitude. The farther scores are from 60 indicates increasing positive or negative attitudes.

\section{Differences Between the Schools}

Scores came from students enrolled in two high schools. The feeder middle schools for School A mandated the use of AR, whereas most students from School B had not used the program. School B had both the highest and the lowest Estes Reading Attitude Scale scores. The mean scores from School A $(M=73, S D=13)$ and School B $(M=69, S D=16)$ were fairly close, but School B had a higher standard deviation from the norm. In order to test if the differences in the Estes Attitude Scale scores from the two schools were significant, a t-test was run. The resulting score is statistically significant, $\underline{\mathrm{t}}(201)=2.451, p<.05$, which indicates that the high school attended had a

small effect on attitude test scores, $r^{2}=0.029$. In this case, the effect size indicates that if all the difference in results is the effect of AR then it can only account for $2.9 \%$ of the effect, which is indeed a small effect. 


\section{Effects of AR on Reading Attitude}

An Analysis of Variance was run to examine the effects of Accelerated Reader (AR) usage on subsequent attitude. There were five levels of this independent variable, ranging from 0 to 4 years of participation. Table 7 shows the number of participants for each of these levels. The Analysis of Variance, focusing on the Estes Attitude Scale scores as the dependent variable, shows no significant difference between years spent in Accelerated Reader and reading attitudes, $F(4,196)=1.615, p<.172, \eta 2=.032$. In other words, participants gained no advantage nor faced a disadvantage on the attitude measure as a function of participating in AR. Table 7 gives the respective means and standard deviations of the Estes Attitude Scale scores as reported by the number of years Accelerated Reader was used.

Table 7: Mean Estes Attitude Scale Scores

\begin{tabular}{|c|c|c|c|c|c|c|}
\hline \multirow{2}{*}{ Years in AR } & \multicolumn{3}{|c|}{ School A } & \multicolumn{2}{c|}{ School B } \\
\cline { 2 - 7 } & $n$ & Mean Score & Standard Deviation & $n$ & Mean Score & Standard Deviation \\
\hline 0 & 10 & 80.70 & 14.97 & 97 & 69.37 & 15.56 \\
\hline 1 & 4 & 74.50 & 9.47 & 2 & 71.50 & 34.65 \\
\hline 2 & 11 & 68.64 & 16.05 & 1 & 56.00 & $\mathrm{n} / \mathrm{a}$ \\
\hline 3 & 55 & 72.02 & 12.71 & 4 & 56.50 & 30.95 \\
\hline $4+$ & 16 & 80.37 & 12.38 & 1 & 70.00 & $\mathrm{n} / \mathrm{a}$ \\
\hline
\end{tabular}

Title Recognition Test

\section{Differences Between the Schools}

The Title Recognition Test is an indicator of the amount of exposure to books student have and correlates directly with the amount read (Pavonetti, Brimmer, and Cipielewski, 2000). School B again had both the highest and lowest scores. The Title Recognition Test scores were very similar in terms of both means and standard 
deviations: School $\mathrm{B}(\mathrm{M}=9, \mathrm{SD}=4.4)$ and School $\mathrm{A}(\mathrm{M}=10, \mathrm{SD}=4.6)$. In order to test if the data from the Title Recognition Test were significant, a t-test was run. The tscore for the Title Recognition Test of 1.903 is not significant, $\underline{\mathrm{t}}(204)=1.980, p<.05$. The results indicated no statistical relationship between the high school attended and the amount of books read.

\section{Effects of AR on Reading Pursuit}

Similarly, an Analysis of Variance using the Title Recognition Test scores as the dependent variable was run to examine the effect of Accelerated Reader usage on later reading pursuit. Table 8 gives the respective means and standard deviations of the Title Recognition Test scores as reported by the number of years Accelerated Reader was used. The data show no significant difference between years spent in Accelerated Reader and the amount read as indicated by the Title Recognition Test, $F(4,199)=1.046, p=.385$, $\eta 2=.021$. As with the answer to the previous research question, performance on the TRT found no advantage or disadvantage from AR participation.

Table 8: Mean Title Recognition Test Scores

\begin{tabular}{|c|c|c|c|c|c|c|}
\hline \multirow{2}{*}{ Years in AR } & \multicolumn{3}{|c|}{ School A } & \multicolumn{3}{c|}{ School B } \\
\cline { 2 - 7 } & $\boldsymbol{n}$ & Mean Score & Standard Deviation & $\boldsymbol{n}$ & Mean Score & Standard Deviation \\
\hline 0 & 11 & 11.45 & 6.04 & 97 & 8.85 & 4.28 \\
\hline 1 & 4 & 6.50 & 4.80 & 2 & 16.00 & 7.07 \\
\hline 2 & 12 & 8.92 & 4.62 & 1 & 7.00 & $\mathrm{n} / \mathrm{a}$ \\
\hline 3 & 56 & 10.18 & 4.46 & 4 & 9.50 & 4.36 \\
\hline $4+$ & 16 & 11.31 & 3.57 & 1 & 6.00 & $\mathrm{n} / \mathrm{a}$ \\
\hline
\end{tabular}

Results from the Interviews

Demographics of the Interview Participants

Twenty-two students participated in the interviews, eleven students from each high school. Because a fairly even distribution of the genders was desired, the 
participants' permission forms in each English class were first sorted into two piles (male and female) and then interview candidates were drawn randomly, but without replacement, alternating the piles until $10 \%$ of that class's participants were interviewed. Most of the interviewed students were white, with only one minority student drawn from School A, as shown in Table 9. One of largest contrasts between the groups was the students' English class levels. Most of the students interviewed at School A were taking college prep English while most of the students interviewed at School B were taking honors English. None of the students at School A were taking advanced placement English, since it was not even offered the year of the study, but four of the eleven students from School B were taking advanced placement English. None of the students interviewed from School B had used AR at all. Most of the students interviewed from School A had used AR approximately three years, with the number of years ranging from zero to nine. 
Table 9: Demographics of the Interview Participants

\begin{tabular}{|l|l|l|l|l|}
\hline & Gender & Race & English Level & Years of AR \\
\hline School A & Male: 5 & White: 10 & Advanced Placement: 0 & $0: 1$ \\
& Female: 6 & Black: 0 & Honors: 3 & 2: 1 \\
& & Hispanic: 1 & College Prep: 7 & $3: 8^{*}$ \\
& & & General: 1 & $9: 1$ \\
\hline School B & Male: 5 & White: 10 & Advanced Placement: 4 & $0: 11$ \\
& Female: 6 & Black: 0 & Honors: 6 & \\
& & Hispanic: 0 & College Prep: 1 & \\
& & Other: 0 & General: 0 & \\
\hline
\end{tabular}

*2 students remembered using AR 2-3 years and 2 students remembered using AR 3-4 years. Both of these categories were included in the 3-year category, since that was the number of years the county mandated use of the program.

\section{Interview Results}

I transcribed the recorded interviews with the assistance of Dragon Naturally Speaking software. After confirming that the transcribed text was in agreement with the recorded narrative, I laid the interview scripts side-by-side so that the data gathered from the interviews could be constantly compared and analyzed. As each question was examined this way, I recorded the key words for each answer in a table in order to detect patterns. (See Appendix G, Trends Found in Interview Data for the complete table of data patterns.)

The Motivation to Read Profile: Conversational Interview served as a template for the interview protocol because it dealt mainly with questions concerning attitude and reading pursuit. The themes that developed along these lines were: Reading Habits, Self-Perception of Reading Ability, and Factors that Stimulate Interest in Reading. Since 
this study focused on the effect of AR use on reading attitude and pursuit, the students that went through that program were asked specifically about its impact on their reading. Reading Habits

The students from the two high schools were similar in many ways, especially concerning their reading habits. Many students from both schools had not read anything outside of school-assigned books within a week of the interview, and reported lack of time due to schoolwork, sports, and part-time employment to be the main constraints to reading more. One girl from School B said, “I don't always have as much time to read [compared to when I was in middle school] because a lot of time we get more work. And then I have a job, and everything." Another girl from the same school stated, "I just read for school-related [assignments], because it seems like I don't have time for just casual reading." Still another girl from School B repeated the same theme, "I have sports, and then when I do have time to read books, they're usually schoolbooks that we're assigned." Students from School A agreed wholeheartedly with this assessment. One boy observed that he hadn't read anything for pleasure since before the school year began because, "I've been so bogged down with schoolwork, because I have an Advanced Placement class and other readings for my other classes." A classmate echoed this idea, "I used to get books a lot from the library [when I was in middle school]. And I used to read a lot more, but now I really can't because I have a lot of schoolwork to do."

Several students from both schools voiced regret that they had less time to read for pleasure. A boy from School B lamented, "I'm the type of person that I would love to just like go into a log cabin and read. And read, and read, and read. But with school, it doesn't seem like I have any time with all the other stuff that I'm involved in. It's kind of sad." This regret over the lack of time available for pleasure reading was repeated by a girl from School A, who said, “As a reader, I don't read that much. I wish I could read 
more. There just aren't enough hours in the day. And especially with school. Not enough hours in the day." This statement is especially poignant based on this particular student's background. She reflected, "I realized that prior to when I was ten, I had never actually read a book for mere pleasure, just for wanting to read it, because first of all there weren't the sources. And I was amazed to find that in the United States, you can -the schools have libraries and you can just check books out. And that's pretty much it. I was so fascinated by it....The schools [in Honduras] didn't have libraries. You were lucky if they had a computer...there was not a public library that I ever knew of."

\section{Self-Perception of Reading Ability}

One of the most apparent differences between School A (the AR group) and School B (the non-AR group), based on the interview answers, was the students' perception of themselves as readers. Juniors from School A reported a heightened view of themselves as readers as compared to students from School B, which agreed with the results of the Estes Attitude Scale. At School A, students' views of themselves as readers ranged from: "I'm an all right reader" to "I'm a pretty good reader" to "I read too much." Only one student from this school said that she was less than average: "I probably don't read as much as I should, but I guess that I'm an OK reader. I read kind of slow, though."

In contrast, students from School B tended to talk more about their reading habits than their abilities when asked their view of themselves as readers. Some talked about how much they read and how they liked reading: "I enjoy reading, but I don't do it a much as I think I should. But I do enjoy reading." Similarly, "I don't read a whole lot, but I read here and there. As I said, I like reading facts more than reading stories." Others talked about what they liked to read: “I view myself as a reader who's not really into fiction: into reading to kind of escape from reality. I'm reading about reality. I'm 
reading about what people do every single day." On a similar trend, but focusing on purpose of reading instead of interests, another student from this school said, "As a reader, I'm just someone who reads for fun." Still others talked about what it would take to entice them to read: 'I'll read if I don't have anything else to do. Like if the power's out, with a flashlight, I'll read."

A few students from School B did rate themselves as readers: One student said she wasn't "the best but [she] could read fairly well," another said he was "reading challenged, as in [he didn't] read enough," and a third reported that she was "not very good. [She] could read better." Only one student from School B reported that she was above average.

When talking about their perceptions of themselves as readers, students from School B were more apt to point out their reading levels as measured by the Standardized Test for Assessment of Reading (STAR) Test, which is the baseline test that AR students take at the beginning of the year to determine their grade equivalent scores and find out their AR reading level and target points. One student reported reading on the $9^{\text {th }}$ grade level in $7^{\text {th }}$ grade, and another one said, "I'm pretty high. Like the last [STAR] test I took I was reading at a college level, and that was at the end of eighth or ninth grade." In contrast, none of the students from School B referred to test scores when asked about their view of themselves as readers.

\section{Factors that Stimulate Interest in Reading}

The students were also split somewhat along school lines when asked about what would get them excited about reading. Although students from both schools said that the enjoyment gained from reading was what drew them to read, the two schools differed starkly in the mention of extrinsic rewards. Students from School A (the AR school) were less apt to get excited about learning from a book than to be excited by the rewards 
and/or prizes that they could earn from reading a book. Four of the eleven students at School A mentioned that they were motivated to read by some type of reward, whether it be AR points, prizes, or Book-It coupons. In contrast, only one student from School B stated that he was motivated by extrinsic rewards, in the form of Book-It coupons.

\section{Interview Results: Students' Perceptions of AR}

The students that had participated in AR were asked at the end of the interview specifically about features of AR and their perceptions of it. These questions were held until the end of the interview in order not to taint the rest of the interview by focusing on AR from the beginning. The questions about AR focused on incentives used, target points and penalties for not reaching these points, and the perceived effect of AR on reading. The students' answers mainly focused on Motivation and Quantity Read, Silent Reading and Improved Reading Skills, English as a Second Language and Improved Reading Skills, Limited Choice, Reading for Points, Lack of Up-to-Date Tests, and Integrity of the Comprehension Tests.

\section{Motivation and Quantity Read}

Many of the students who had participated in the AR program remembered the program well and had quite a bit to say about it. Several students from School A believed that AR had positive effects on their growth as readers, even while many of them noted the compulsory nature of the program. One girl noted, "Accelerated Reader made me read a lot more and made me comprehend a whole lot more than I usually did...I think that being forced to read the book, even though I didn't like it, it made me think that reading is OK, because I didn't use to like reading. So, it's had an effect on how many books I read." The motivational aspect of AR was echoed by a male classmate, who credits the program with getting him interested in reading through the extrinsic rewards until he was finally reading for intrinsic rewards. "[AR] was the thing - well, one of the 
things that got me interested in reading, but it really just helped me be able to comprehend [the books] better...It was really reading to get points and therefore prizes or whatever. And as I read and got the stuff, I just began to pick it up and then I would read just for fun." One boy, who had used AR for three years in elementary school, said, "I think that Accelerated Reader is a very good program because it helps create the students into different people. It helps them to grow into a mature kind of person. It helps them to become what they should be, and not become some sort of person who is just wasting away their life - just thinking about what they should do." Another girl stated, “Accelerated Reader was a big [motivational factor], because it was kind of like, we had to read, so there was no choice in reading. But now that I think back, what that did was to help me to understand that books do help you in a lot of ways... At the time it was more of a necessity that you had to do it. You didn't really have a choice, but it did help."

\section{Silent Reading and Improved Reading Skills}

The AR program was credited with improving reading skills not only due to increasing motivation as discussed previously, but also through a specific feature of the program, Silent Reading. Since School A's district mandates that all students in middle school read silently for 30 minutes daily as part of the AR program, this particular feature of the program received its mention. One girl stated that she enjoyed the portion of the program that mandated that all the students at the school spend a half hour silently reading. "I remember that I thought Accelerated Reader was a very, very good time of the day, because I enjoyed reading." She credited AR with enlarging her vocabulary, improving her writing, and increasing the amount she read daily. 


\section{English as a Second Language and Improved Reading Skills}

The AR program was also credited with helping an English as a Second Language student learn English by a Hispanic student, who moved to the United States from the Honduras when she was in fifth grade. "Middle school was really hard, because I was just trying to learn how to read, but I will say that I had very good reading on the Accelerated Reader program, to the point that when I was in seventh grade, I was already on a ninth grade level. So, [my reading habits] changed drastically."

\section{Limited Choice}

However, there were some negative aspects of AR that were also shared by its former participants. The same Hispanic student that credited AR with improving her English complained that the program limited her to boring, easy-to-read books. "When I was using [AR], I actually felt quite limited, because my score was low, but the books that were for that score were not that good. I found them very boring. I had a really low score, and there was only a stack that big [gestured with fingers] that I got to choose from. But as it got better, I got more options...We had to pick something within the score. And my score was so low, since it was sixth grade. But it was just a pile of books...I had before, over the summer, [read higher level books]. But they had this pile, and they were very boring."

\section{Reading for Points}

Two girls stated that the pressure to read to get a set amount of points by a set time was taxing. One stated, "I didn't like it at all, actually" when asked if she remembered using AR. She expounded, “I just really didn't like the pressure of you have to read this book and you have to take this test. I just didn't like being put under that timeframe that we had to do it in." The other reminisced, "I think that I started [the AR program] in fifth or sixth grade. That's when I started the whole Accelerated Reader 
thing - taking the test and then determining what book I had to read. Which made it harder on me, because since it was such a high level that I was reading, then I had to get bigger books than everybody else...I never really did get my Accelerated Reader score. It was always like too far, like I didn't get that many points because my books were so big, so it would take me a long time to read them... [The penalty for that was] bad grades. My cousin's going through that now. She's getting an F in reading because of her Accelerated Reader."

\section{Lack of Up-to-Date Tests}

One boy reported having problems finding a test for a book he had read. "You had to pick some [books] that were in the school library or you could possibly go on the internet. And I remember one book. It was Holes, but they didn't have the test at my school, so I think I had to read another book quickly to make up for that."

\section{Integrity of Comprehension Tests}

The integrity of the program's tests were called into question by a girl, who confessed that she skimmed books for the factual information that might be on the AR tests and shared information with her peers to pass the tests and meet the point quotas. "I was trying just to go in and pick up a book, skim through it, make sure I knew important information, and then go take the tests. I didn't really care about the books because I knew I had to get the points, so I wasn't really worrying about which books I would read. So, it wasn't something that I wanted to do. I would complain to my mom a lot about Accelerated Reader. I didn't want to take it...I believe that [AR] has helped me to look for important information really quickly to put into a paper or a paragraph, or whatever. But, I mean, I don't think it's done anything else for me.” 


\section{Summary of Interview Results}

The interviews mainly indicated that many of these high school students realize that they should read more and would like to read more if they could find the time. Several students expressed excitement to read for the intrinsic pleasures found in reading.

The most obvious differences appeared to be the manner in which the AR and non-AR students referred to themselves as readers (ability versus their reading practices, respectively) and what they said motivated them to read (extrinsic rewards versus learning).

Students that had previously used the AR program both praised and criticized it. Former AR participants praised the program mostly for building literacy skills (vocabulary, comprehension, writing skills), aiding in learning English, providing time for students to silently read, and for motivating them extrinsically and eventually intrinsically. However, these same participants criticized the program for the limitations it set of having to pick a book from a given level (both by high and low testing students), for exerting pressure on students to make their point goals or reap the consequences in poor grades, for not providing tests for newly released books, and for promoting situations that tempted students to cheat in order to reach their target point levels. 


\section{CHAPTER V: DISCUSSION}

There were two major research questions for this study: What are the long-term effects of participation in Acclerated Reader (AR) on reading attitude as measured by the Estes Reading Attitude Scale and on reading pursuit as measured by the Title Recognition Test. Interviews with a subset of participants allowed for additional exploration of reading attitude and pursuit. Results indicated that participation in AR had no effect on reading attitude or reading pursuit. This is an important finding because it brings into question the effectiveness of the AR program to "build lifelong readers," which is what its marketers claim and which is what the schools seek. The interviews revealed that the students from both the AR and the non-AR groups were similar in that they felt that they did not read as much as they would like to and that they regretted the lack of time to read for pleasure. Several also stated that the intrinsic pleasure of reading was what enticed them to read. The interview responses also indicated that AR participants were more motivated by extrinsic rewards than their non-AR peers and that AR participants tended to rate themselves on an achievement-based scale while non-AR users evaluated themselves based on what, why, and how much they read. This section will probe into these results, link them with previous research, and look ahead to areas of future research.

\section{AR Effects on Achievement}

The preponderence of the research conducted concerning the AR program has focused on whether or not it affects reading achievement. Although the results have generally found a positive correlation between AR and standardized test scores (Paul, 1992; 1993; 1996; Peak \& Dewalt, 1994; Vollards, Topping, \& Evans, 1999; Knox, 1996; Holman, 1998; Harrell, 1999; Bork, 1999; Kunz, 1999; Howard, 1999; Morse, 1999; Griffin, 2000; Knapik, 2002; Sims, 2002; Hagerman, 2003; Steele, 2003; 
Schreiber, 2004; Kobel, 2005; Walker, 2005; Paul et al., 1997; Jones \& Coody, 2001; Holmes \& Brown, 2003; Fine, 2000; Smith \& Clark, 2001; Topping \& Fisher, 2001), questions and doubts have plagued these findings. Most of the studies have a direct connection to the Renaissance Learning Company, which manufactures and sells the AR program. Additionally, most of the studies are correlational in nature and rely on the comparison of pre- and posttest data from various standardized tests. The lack of independent research calls into question the reliability of these studies, which is why Accelerated Reader has not met federal standards as a reading program, which has been "proven, with independent research to be effective" (Chenoweth, 2001, p. 2). In other words, Accelerated Reader has not met the minimum federal standards for scientifically based reading research.

\section{AR Effects on Reading Attitude}

A handful of studies have examined the immediate effects of AR on reading attitude. These studies have produced mixed findings. Two studies concluded that AR led to increased reading attitudes (Smith \& Clark, 2001; Sims, 2002), and two other studies concluded that AR led to declining reading attitudes (Watts, 2004; Eliason, 2005). One study (Rogers, 2000) found that AR increased students' perceptions of themselves as readers. However, all of these studies's participants were using AR at the time of the study. Various methodologies were used in these studies: two of the studies (Smith \& Clark, 2001; Watts, 2004) used surveys of students, teachers, and/or parents to arrive at their data, two of the studies used reading attitude tests (Eliason, 2005; Sims, 2002), and one study (Rogers, 2000) used interviews.

The current study delved into new territory by examining the long-term effects of AR instead of its immediate effects and by taking into consideration how the duration of time spent in the program affects reading attitude and pursuit. This is important because 
the true measure of a program should be its long-term effects and not simply its immediate effects. This is especially true of a reading program, because reading is not only a critical skill that is useful in all educational and employment endeavors, but it can also be a passion that shapes and expands the readers' lives. Reading attitude and pursuit were specifically chosen to be the focus of this study, because they are indicators of whether or not a person is a "lifelong reader." As Estes noted in his study, "The value of reading ability lies in its use rather than its possession" (1971, p. 135). In other words, reading skills as measured on achievement tests can only go so far. The true measure of a reader must include his/her reading attitude and reading habits, or pursuit.

The findings of this study showed that AR has no significant long-term effects on either reading attitude or pursuit but indicated that use of the program led to reliance on extrinsic rewards for motivation and to self-perceptions based on achievement and grade equivalency scores. It also found that use of the AR program led to reading for points and exerted undo pressure to reach point goals, which was similar to the results from Rogers (2000). Since this study used interviews to compare students' reading attitudes instead of surveys as in some of the previous studies, it increased the ability to probe each answer further than they could be by the surveys. Finally, the use of both the Estes Attitude Scale and the interviews in this study, instead of just one measure as in many of the previous studies, allowed for triangulation and a deeper understanding of the results (Patton, 2002).

\section{AR Effects on Reading Pursuit}

Pavonetti, Brimmer, and Cipielewski (2000) studied the effects of AR use on reading pursuit by giving a Title Recognition Test (TRT) to two groups of students, one that had used AR and one that had not and found a decrease in the amount of books read by the AR participants. The present study used the TRT developed by Pavonetti, 
Brimmer, and Cipielewski as a template to develop a TRT for use with high school students. The TRT was revised because the one previously developed and tested was aimed for use by middle schoolers and this study was conducted with high school juniors. This study agreed with Pavonetti, Brimmer, and Cipielewski's findings that AR had no effect on long-term reading pursuit, but extended the previous research since this study examined a longer period of discontinuance and because the age groups were markedly different.

\section{AR Effects on English as Second Language Learners}

Castillo (2002) studied the effects of AR on fifteen English language learners' achievement and found a significant increase in Standardized Test for Assessment of Reading (STAR) test scores, with the exception of one student, who dropped almost a year and a half grade equivalency level. This agrees with the perceptions of the English as a Second Language learner who was interviewed and credited AR with helping her learn English and raise her grade equivalency score on the STAR test quickly. Once again, this study added to the previous research because it examined the long-term effects of the AR program and used methods other than the analysis of test scores.

New Discoveries

This study delved into new territory by examining the long-term effects of AR instead of its immediate effects and by taking into consideration how time spent in the program affects reading attitude and pursuit. It found that many of the long-term effects of $A R$ on reading attitude and pursuit were similar to its short-term effects: the AR program had little or no effect on reading attitude and no effect on reading pursuit. Reading attitude and pursuit are critical components of reading motivation and are indicators of reading becoming a lifelong habit. Readers' self-confidence, reading abilities, and attitudes toward reading tend to increase the amount read, which 
subsequently increases these motivational factors. This positive upward spiral builds on itself and is evident in avid readers (Tompkins, 2004; Wigfield, A., \& McCann, A.D. 1996/1997, Edmunds \& Bauserman, 2006; Morgan \& Fuchs, 2007; Gambrell, Palmer, Codling, \& Mazzoni, 1996; Jones, 1994).

The use of interviews in this study increased the likelihood of understanding reader motivation. Two themes emerged from the interviews that, while not completely new, are somewhat on the forefront of research in this area. One of these was the tendency of former AR participants to evaluate themselves as readers based on their grade equivalent scores. The other was these same students' focus on extrinsic rewards and prizes as factors that would motivate them to read. The use of extrinsic rewards has particularly drawn intense criticism with regard to the AR program both through research (Pavonetti, Brimmer, \& Cipielewski, 2000) and the available literature (Carter, 1996; Chenoweth, 2001), because it is feared that the constant use of extrinsic rewards will eventually lead to the extinction of the very habit that the program desires to build. The obsession with extrinsic rewards, points, and grade equivalency scores that AR sometimes spawns is a great concern. Comments such as "Getting points is the main thing"” (Rogers, 2000, p. 67) and "It was really reading to get points and therefore prizes or whatever" cannot be overlooked or glossed over. These extrinsic rewards, computed goals, and ready-made identities as readers are no match for intrinsic rewards, desire to learn, and knowledge of reading interests and motivation. As Carter warns, "In the process [of restricting books and using extrinsic motivators], we may not only turn children off to school books, but may lose lifetime readers" (1996, pp. 23-24). In other words, by jumping on the AR bandwagon and listening to the motto that AR will build lifelong readers, we may be actually doing the opposite, and reducing the number of lifelong readers. 
This study additionally found that high school students, in general, did not read much outside of schoolwork and regretted the lack of time to read. Extra-curricular activities, schoolwork, and employment were all blamed for the lack of time for pleasure reading. This is of great importance, because if students' reading activity is restricted, it could diminish one of the very activities that is of highest concern in the nation (Sweet, 1996; Aspey, Walsh, \& Yudof, 2005; Gooding, 2000). Because the amount of reading affects achievement (Holmes \& Brown, 2003), the limitation of reading time could be far-reaching, to other subjects and beyond high school years.

\section{Implications}

There are several implications that can be made from the results of this study. Commercial claims touting stimulation of reading motivation, attitude, and pursuit are placed into question by this study. For example, AR's claims that it "instill[s] a lifelong love of reading in all...students and help[s] them achieve reading success" (Accelerated Reader website) and that "students who never read before suddenly become voracious readers after they experience success with Accelerated Reader" (Swanson, 2000 as cited in Pavonetti, Brimmer, \& Cipielski, 2000) are brought into question by this study's findings, which show no statistical difference in reading attitude or pursuit between AR and non-AR students. Moreover, it appears that use of the program may actually make the AR users more dependent upon extrinsic rewards rather than developing an intrinsic love of learning.

Indeed, the heavy emphasis on extrinsic rewards and prizes by some of the schools that use this program should be examined in light of the interviews. Those students that had been rewarded heavily listed extrinsic rewards as the factors that would motivate them to read, whereas the students that had not gone through the AR program, and presumably had not been rewarded as heavily, stated that they read for the pleasure 
inherent in reading or in order to learn. Research has shown that although extrinsic motivation may be helpful to entice unmotivated readers to read more, the extrinsic motivators should be limited both in terms of size of the reward and length of the reward program (Johns, 1997; Enmunds \& Bauserman, 2006). "The goal of a reading program is for reading to be rewarding rather than rewarded" (Johns, 1997, p. 2).

Classroom teachers should additionally be aware of the importance of allotting a silent reading period. The AR program was partially built around research that shows the importance of silent reading time, and the importance of this time was also indicated by the students interviewed in this study: "I remember that I thought Accelerated Reader was a very, very good time of the day, because I enjoyed reading." Research confirms that silent reading time is important not only because it creates an environment for children to enjoy reading but because "When time is set aside for independent reading and monitoring, reading achievement improves" (Vollards, 1996 as cited in Scott, 1999, pp. 22-23). Classroom teachers that do not use AR or similar programs should incorporate the practice of silent reading time into their programs. This should not stop at middle school, but should continue through high school. Perhaps setting aside a period for silent reading is most important in high school, when students have increased demands on their time. The longing for more time to read for pleasure was repeated throughout the interviews from both schools. Many of the students had not read anything outside of school-assigned books within a week of the interview, and reported lack of time due to schoolwork, sports, and part-time employment to be the main constraints to reading more, as is apparent from their comments: 
- 'I don't always have as much time to read [compared to when I was in middle school] because a lot of time we get more work. And then I have a job, and everything."

- 'I just read for school-related [assignments], because it seems like I don't have time for just casual reading."

- "I have sports, and then when I do have time to read books, they're usually schoolbooks that we're assigned."

- 'I've been so bogged down with schoolwork, because I have an Advanced Placement class, and other readings for my other classes."

- "I used to get books a lot from the library [when I was in middle school]. And I used to read a lot more, but now I really can't because I have a lot of schoolwork to do."

With this consensus of the lack of time for reading and the desire to read, it makes sense to adopt silent reading programs at all levels of education.

Classroom teachers should also be aware of the link of self-selection of books with children's motivation to read (Angeletti, 1991, Lesesne, 1991), and allow times for students to select their own books. Binder and Hitick (1996) identified six behaviors and attitudes that are indicative of being motivated to read: deciding for oneself what, when, and where to read; creating reading opportunities; wanting to read; choosing to read for a variety of reasons; valuing reading; and having self-confidence pertaining to reading ability. These behaviors and attitudes are as important in high school as they are in elementary school, as shown by the interviews. For instance, one boy indicated how interest in a particular book and wanting to read affects him, "If I like it, I read it fast, but if I don’t it just drags on.” Another girl expressed being motivated by self-selection of 
books, "Mostly [being excited about reading books] is a self-wanting. I want to read them. Yes, my friend recommends them, but she doesn't force me to read them. I decide whether I want to read them or not." One boy contrasted the books that teachers assigned or recommended with the books that he would choose to read on his own, "There have been teachers that encouraged us to read, but they'd usually encourage novels or stuff like that. And as I said, I'm not big on stories so much as facts, so for the last few years, I'd just read books that interested me rather than something that people recommended." Another girl was quite blunt when she was asked about what got her interested in books, “Choice is very important. In today's education, you see a lot of forceful guidelines that teachers are asked to put upon students, and a lot of students are unwillingly reading. So I know I find myself even not wanting to read books that I'm supposed to." In light of these statements, it must be asked whether it is more important to have students "unwillingly read" the same books or if more choice can be given; if conformity is more important than motivation.

Giving students an idea of their reading ability could be an important factor in helping students gain an accurate perception of themselves as readers and aiding students choose books suited to their reading ability. When talking about their perceptions of themselves as readers, students from School A were more apt to point out their reading levels as measured by the Standardized Test for Assessment of Reading (STAR) Test, which is the baseline test that AR students take to determine their grade equivalent scores, or to rank their reading ability. One student reported reading on the $9^{\text {th }}$ grade level in $7^{\text {th }}$ grade, and another one said, "I'm pretty high. Like the last [STAR] test I took I was reading at a college level, and that was at the end of eighth or ninth grade." In contrast, none of the students from School B referred to test scores when asked about their view of themselves as readers, and few of these students ranked themselves by 
ability. The knowledge of reading ability could help students form a more accurate perception of themselves as readers, gain confidence to try more difficult books, and have a positive effect on their attitude toward reading. However, overemphasis on reading levels and limiting choice of books to those levels could stifle students' development of a well-rounded understanding of themselves as readers.

The findings of this study suggest implications for school leaders also.

Administrators need to examine many of the same issues as classroom teachers, and even develop some school-wide programs around these ideas, such as school-wide silent reading, the extent to which a school will use a given program, and schoolwide incentive programs.

Administrators should examine what the role and extent of extrinsic rewards should be. Care should be taken so that "low-level quizzes and prizes [do not] turn reading into an empty contest and actually discourage reading" (Chenoweth, 2001, p. 1). Since many of the interviewed participants of this study referred to these extrinsic rewards, primarily if they were from schools that used AR, this appears to be an important area to consider. As Betty Carter, an associate professor in the School of Library and Information Studies at Texas Woman's University warns, "Reward readers may never discover solutions for their blocked motivation if they succeed in looking like readers and acting like readers rather than becoming readers" (Carter, 1996, p. 25).

Schools that base grades on whether or not target points have been achieved may want to reconsider this policy. Schools should examine whether the goal of reaching target points is more important than reading a book that may require more time than that given to accumulate target points, as illustrated by the interviews from this study as well as the study by Rogers (2000). One girl's complaint about this policy from this study cannot be overlooked: "[My grade equivalency score on the STAR test indicated] a high 
level that I was reading, then I had to get bigger books than everybody else...I never really did get my Accelerated Reader score. It was always like too far, like I didn't get that many points because my books were so big, so it would take me a long time to read them... [The penalty for that was] bad grades. My cousin's going through that now. She's getting an F in reading because of her Accelerated Reader." If STAR test scores lead students to read longer and more difficult books, but the timeframe to read these books is the same as it is for students with shorter, easier books, it would make sense to either extend the time period for the students reading the longer books or to allow them to confirm that they are reading the books at a reasonable rate in some other way than an AR test. After all, the goal of the reading program should be to promote reading - not the accumulation of points.

Moreover, the use of the detailed-based AR comprehension tests should be reconsidered. These tests are used to confirm that the books have been read, and the percentage correct on the tests is used to determine the amount of points awarded the students. However, the use of solely recall level tests, forces readers to read completely efferently (to gather and retain details) rather than allowing readers to adjust their reading stance based on the type of books that they are reading (Rosenblatt, 1994). Students should also be encouraged to talk about books, use key elements of books such as the back of the book summary to help them choose books, and recommend books to each other. In this way, the students will not only have more authentic aesthetic responses to books, but they will also learn more about their own reading preferences and how to effectively choose books (Rinehart, Gerlach, \& Wisell, 1998). Teachers need to provide opportunities for students to respond to books in a more authentic manner, to discuss books among themselves, and to simply enjoy reading. 
In this age of increasing technology, it is without a doubt that computerized programs, with all the benefits and detriments that go with them, are here to stay. Coupled with the increased demand for teacher accountability, it may sometimes seem that the easiest thing is to adopt computerized programs that track achievement and progress. However, it is important, both for the schools and the creators of educational programs to constantly examine the goals of the programs and to monitor them to see if these goals are being met without unwanted side effects. In this case, it is important to weigh the annual cost of the AR program, the side effects of using extrinsic rewards, and the consequences of using only detail-oriented recall tests with the ease of use, the ability to track students' reading, and the capability to assess students' reading levels. It is equally important to consider the other options to each program. The AR program has many research-supported components, such as silent reading, monitoring and nudging up students' reading levels, and self-selection of books. These components are not the sole proprietary of AR, and can be easily integrated into any reading program. Since the best points of AR can be readily adopted to currently used reading programs with little cost or effort, it would make sense to do so, and use the funds set aside for the AR program to stock the library with a plentitude of books.

In the case of AR, it is not enough to simply say that "students who never read before suddenly become voracious readers after they experience success with Accelerated Reader" (Swanson, 2000 as cited in Pavonetti, Brimmer, Cipielewski, 2000, p. 4). The program manufacturers must seriously examine the effects of extrinsic rewards and prizes, the effects of limiting the selection of books, and the effects of asking low-level questions on quizzes. 


\section{Conclusions}

The AR program is based on the theory that increasing the quantity and simultaneously increasing the difficulty of what is read will improve reading vocabulary and comprehension, which in turn will increase motivation to read (Holmes \& Brown, 2003). However, critics of the program ask,

Do they [the students] read because they love to or because they have to, and is Accelerated Reader helping schools encourage lifelong readers, or is this entire program a misuse of computer technology that could better be used elsewhere?... Is Accelerated Reader's use of computer technology to track what is read, deliver and score factual tests, and maintain a progress log actually akin to "deploying an army to kill an ant"? (Carter, 1996, pp. 1, 25).

The present study has found that the use of AR had no long-term effects on reading attitude or pursuit. Indeed, it does seem to be a senseless use of educational funding, when other reading programs seem to do just as well at building "lifelong readers" without the side effect of also building extrinsic reward seekers.

The review of the literature found ample studies that indicated that AR use increased reading achievement. However, these studies have been shown to be deficient because many of the researchers had a direct connection with the company and most of the studies were correlational in nature and relied on the comparison of pre- and posttest data from various standardized tests. The lack of independent well-structured studies casts doubts on the true effectiveness and worth of this program.

This particular study did not look at the AR program's effect on reading achievement, which is what most of the previous studies examined (Paul, 1992; 1993; 1996; Peak \& Dewalt, 1994; Vollards, Topping, \& Evans, 1999; Knox, 1996; Holman, 1998; Harrell, 1999; Bork, 1999; Kunz, 1999; Howard, 1999; Morse, 1999; Griffin, 
2000; Knapik, 2002; Sims, 2002; Hagerman, 2003; Steele, 2003; Schreiber, 2004; Kobel, 2005; Walker, 2005; Paul et al., 1997; Jones \& Coody, 2001; Holmes \& Brown, 2003;

Fine, 2000; Smith \& Clark, 2001; Topping \& Fisher, 2001). Instead, it analyzed the effect AR use in middle school had on high school juniors' subsequent reading attitudes and reading pursuit. It was found that AR had no statistically significant effect on either reading attitude or pursuit when analyzed according to the number of years AR was used. Therefore, this study did not support the motto of AR, which states that it will build "lifelong readers." Instead, it called into question the practice of relying on extrinsic rewards to generate the love of reading, the limitations placed on students when they select books, the focus on grade equivalent scores as measures of reading abilities, and the penalization in terms of poor grades for unmet point goals.

After all is said and done, the relationship of this rising generation to reading is what needs to be focused on. Being able to read is of utmost importance, but the desire and drive to read is equally important. The AR program was created in order to strengthen students' motivation to read as well as to increase the amount of books they read. Many of the factors of the program have some merit and are used in many reading programs:

Certainly, setting aside a portion of the school day to allow students time to explore the world of books is a worthwhile program in the school day, because it allows that desire to read to flourish and gives opportunity for students to fill their thirst for books. This is not only important in early grades, but must be implemented through high school as well. The interviewed students in this study expressed their thirst to be able to read for pleasure and their inability to find time to do so. This was especially expressed by a boy who lamented, "I'm the type of person that I would love to just like go into a log cabin and read. And read, and read, and read. But with school, it doesn't seem like I 
have any time with all the other stuff that I'm involved in. It's kind of sad." It does seem sad - and wrong - to keep students from reading. If reading is a priority of education, then educators should find a way to make time for it - through and including high school.

Monitoring students' choice of books is equally important for many reasons.

First, as in the AR program, it allows teachers to make sure students are reading books at their independent reading level. However, monitoring book choice should go beyond simply monitoring the difficulty level of books chosen (Angeletti, 1991). Students should be observed to ensure that they are developing a method of choosing books based on their distinctive tastes and needs, and that should be followed up by further observation to make sure students understand what they are reading. Furthermore, monitoring choice should not simply be focused on grade equivalency levels. Interest is just as important as reading level. This is especially important to keep in mind when students choose nonfiction books. Students may be able to read nonfiction books above their instructional reading level because they have the appropriate vocabulary on a subject that interests them. Conversely, books on that same subject that are below their instructional level should not be banned simply because of the books' level. Students should not be denied books based on the books' levels, but they should be monitored and guided in their reading.

The decision to use extrinsic rewards to further educational goals of any sort and/or the extent to which they are used is a topic of much debate. The AR program's emphasis on extrinsic rewards was repeatedly criticized by the available literature (Chenoweth, 2001; Carter, 1996) and was a source of concern in this study based on the interview results that indicated that the students who used AR listed extrinsic rewards as motivating factors much more than their peers who had not used AR. 
It is always prudent to examine any program in order to understand the theories behind it and to study its effects. This study calls into question the claim of AR that it will "instill a lifelong love of reading in all...students and help them achieve reading success" (Accelerated Reader website, emphasis added) and calls for additional examination of the program.

\section{Recommendations for Future Work}

Bearing in mind the limitations inherent in this study and the importance of examining this widespread reading program, more extensive studies are needed in order to be able to reach more conclusive results that can be generalized to a wider population. Therefore, it is recommended that similar studies that include other regions, ethnic groups, and socioeconomic groups be undertaken. Also more longitudinal studies that encompass all the years from elementary school through post-graduate years should be pursued, including studies with interviews during AR and after the program has been terminated. Since there have been few studies on the effects of computerized reading programs on reading attitude and pursuit, these are areas that need further study.

Additionally, the need for further study into high school students' reading habits, their daily obligations that constrain them from reading, and their reading attitudes was brought to light by the interviews. Students concurred that they longed for more time to read but could not find it due to their daily obligations, including schoolwork, extracurricular activities, and employment. Some students remarked that they couldn't wait to finish school so that they could read more. With this in mind, research should examine the reading habits and constraints on reading for schoolchildren, especially in the upper grades as well as their reading motivation. With the idea that silent reading time should be included in the school day through high school, the effects of adding this program at the high school level should also be probed into. 
Furthermore, the relationship of effective teachers with reading programs should be examined. As Richard Allington points out, "Researchers deal in probability not absolutes. Teachers deal with variation, not sameness" (2003, p. 463). In other words, regardless of the research findings on any given program, true teaching effectiveness is based on the interaction of teachers with students. Allington emphasizes that effective teachers adapt their techniques to their students' needs instead of wholeheartedly pledging fidelity to any reading program. Therefore, the characteristics of effective teachers as well as the manner in which they interact with students and their use of curricular programs should be studied.

This study used mixed methods, both quantitative and qualitative, to study the effects of AR on reading attitude and pursuit. The quantitative methods provided a method to compare the effects objectively and were worth the amount of time involved in collecting and analyzing the data. However, the meat of this research was found in the interviews, where the students were given a voice. Since motivation to read is so multifaceted, encompassing reading attitude and reading pursuit as well as other nebulous factors, it is crucial for studies about these qualities to include interviews, which allows the participants' voices to be heard. 


\section{REFERENCES}

Allen, L., Cipeilewski, J., \& Stanovich, K.E. (1992). Multiple indicators of children's reading habits and attitudes: Construct validity and cognitive correlates. Journal of Educational Psychology, 84, 489-503

Angeletti, S.R. (1991). Encouraging students to think about what they read. The Reading Teacher, 45, 288-296.

Allington, R. (2003). Ideology is still trumping evidence. Phi Delta Kappan, 86(6), 462- 468.

Aspey, S., Walsh, E., \& Yudof, S. (2005, February 7). President's FY 2006 budget focuses resources on students who need them the most. Retrieved February 10, 2005 from http://www.ed.gov/news/pressreleases/2005/02/02072005.html

Biggers, D. (2001). The argument against Accelerated Reader. Journal of Adolescent \& Adult Literacy, 45(1), 72-75.

Blystone, J. (2006, February). Renaissance Learning celebrates 20 years of accelerated learning. Renaissance Learning, Inc.: Better Data, Better Learning.

Blystone, J. (2006, January). Renaissance Learning products receive accolades from federally-funded organizations. Renaissance Learning, Inc.: Better Data, Better Learning.

Bork, R.D. (1999). The effectiveness of the Accelerated Reader Program on improving student instructional reading levels as measured by the Standardized Test for Assessment of Reading. (Doctoral dissertation). Graduate School of St. Louis University. 
Bullock, J.C. (2005). Effects of the Accelerated Reader on reading performance of third, fourth, and fifth grade students in one Western Oregon elementary school. (Doctoral dissertation). Graduate School of the University of Oregon.

Carter, B. (1996). Hold the applause? Do Accelerated Reader \& Electronic Bookshelf send the right message? School Library Journal, 22-25.

Castillo, D. (2002). The effect of Accelerated Reader on the reading comprehension of third grade students (Master's thesis). California State University.

Chenoweth, K. (2001). Keeping score [Electronic version]. School Library Journal, 47(9), 48-52.

Crawford, R. (2001). Virginia elementary students surpass state averages on standards test. Wisconsin Rapids, WI: Educational Research Department.

Dickerson, K. A. (2005). The relationship between Accelerated Reader points and postsecondary education admission factors. (Doctoral dissertation). Wilmington College.

Ediger, M. (2002). Computers, technology, and the reading curriculum. (Report No. CS 511 326). Denver, CO: Education Commission of the States. (ERIC Document Reproduction Service No. ED 468 662)

Edmunds, K.M., \& Bauserman, K.L. (2006). What teachers can learn about reading motivation through conversations with children. The Reading Teacher, 59(5), 414-424.

Eliason, B. (2005). Effects of Accelerated Reader on student attitudes toward reading. (Doctoral dissertation). Graduate School of the University of Oregon.

Estes, T.H. (1971). A scale to measure attitudes toward reading. Journal of Reading, (15) 135-138 
Fine, A. (2000). Alabama elementary school receives governor's trophy for most improvement after implementing Reading Renaissance. Wisconsin Rapids, WI: Educational Research Department.

Gambrell, L.B., Palmer, B.M., Codling, R.M., \& Mazzoni, S.A.. (1996). Assessing motivation to read. The Reading Teacher, 49(7) 518-533.

Gibson, M.T. (2002). An investigation of the effectiveness of the Accelerated Reader Program used with middle school at-risk students in a rural school system. (Doctoral dissertation). Mississippi State University.

Greenwalt, V. (2004). Going beyond the debate: Using technology and instruction for a balanced reading program [Electronic version]. Teacher Librarian, 32(2) 12-15.

Griffin, T.F. (2000). A causal comparative study on the effects of Accelerated Reader. (Doctoral dissertation). The University of North Carolina at Charlotte.

Hagerman, T.E. (2003). A quasi-experimental study on the effects of Accelerated Reader at middle school. (Doctoral dissertation). Graduate School of the University of Oregon.

Harrell, J.P. (1999). Independent readers increase library use. (Doctoral dissertation). Grand Valley State University.

Holman, G.G. (1998). A correlational study to determine the effects of the Accelerated Reader Program on the reading comprehension in Early County, Georgia. (Doctoral dissertation), University of Sarasota. 
Holmes, C.T., \& Brown, C.L. (2003, February). A controlled evaluation of a total school improvement process, School Renaissance. (Report No. EA 032 402). Paper presented at the meeting of the National Renaissance Conference, Nashville, TN. (ERIC Document Reproduction Service No. ED 474 261)

Howard, C.A. (1999). An evaluation of the Accelerated Reader Program in Grades 35 on reading vocabulary, comprehension, and attitude in an urban southeastern school district in Virginia. (Doctoral dissertation). Old Dominion University. Johns, J.L., \& Lenski, S.D. (1997). Improving Reading: A Handbook of Strategies ( $2^{\text {nd }}$ ed.). Dubuque, IA: Kendal/Hunt Publishing Company.

Jones, A.J., \& Coody, K. (2001). Five-year gains of almost 30 percentiles in ITBS achieved by Georgia primary school. Wisconsin Rapids, WI: Educational Research Department.

Keller, J. (2000, March). Fighting like C-A-T-S AND D-O-G-S. National Right to Read Foundation. Retrieved February 25, 2006 from http://www.nrrf.org/article keller 3-3-00.htm

Knapik, P.J. (2002). The effect of the Accelerated Reader Program on Student Achievement: A comparison study. (Doctoral dissertation). The Rossier School of Education, University of Southern California.

Knox, M.L. (1996) An experimental study of the effects of "The Accelerated Reader Program" and a teacher directed program on reading comprehension and vocabulary of fourth and fifth grade students (Doctoral dissertation). University of South Florida

Kobel, P. R. (2002) Accelerated Reader: Its impact on the reading levels and state testing scores of $10^{\text {th }}$ grade students in Delaware's Milford High School. (Doctoral dissertation). Wilmington University. 
Kunz, J.R. (1999) Does the Accelerated Reader program have an impact on the improvement of children's reading scores in Illinois? (Doctoral dissertation), Saint Louis University.

Lafferty, I.O. (2005, January). A brand new read. Technology \& Learning, 14-19.

Lance, B., Beiler, J, Warren, J., \& Slayden, T. (2002). Achievment gap at a Texas elementary school reduced by $88 \%$. Wisconsin Rapids, WI: Educational Research Department.

Lawson, S. (2000). Accelerated Reader boost student achievement. Wisconsin Rapids, WI: Educational Research Department.

Marston, D., Deno, S., Kim, D., Diment, K., \& Rogers, D. (1995). Comparison of reading intervention approaches for students with mild disabilities. Exceptional Children, 62, 20-37.

Mathis, D. (1996). The effect of the Accelerated Reader program on reading comprehension. (Report No. CS 012 573; Eric Document Reproduction Service No. ED 398 555). Retrieved January 28, 2006 from http://www.eric.ed.gov/ERICDOCS/data/ericdocs2/content_storage 01/00000 $\underline{00 \mathrm{~b} / 80 / 21 / \mathrm{pc} / 7 \mathrm{c} . \mathrm{pdf}}$

Morgan, P.L., \& Fuchs, D. (2007). Is there a bidirectional relationship between children's reading skills and reading motivation? Exceptional Children, 73(2), 165-183.

Morse, D.J. (1999). Accelerated Reader. Does it work? (Master's thesis). Grand Valley State University.

Moyer, M. (2006). Accelerated Reader sparks high school reading excitement. Knowledge Quest, 35(1), 34-39. 
National Center for Educational Statistics. CCD public school data 2004-2005

school year. Retrieved November 25, 2006 from

http://nces.ed.gov/ccd/schoolsearch/school_detail

Neufeldt, V. (1991). Webster's New World Dictionary of American English (3 ${ }^{\text {rd }}$ ed.). New York: Simon \& Schuster.

Northwest Regional Educational Laboratory \& The Center for Comprehensive School Reform and Improvement. (2004, January). School Renaissance (K-12). The Catalog of School Reform Models. Retrieved January 28, 2006 from http://www.wnrel.org/scpd/catalog/ModelDetails.asp?ModelID=48

Otaiba, S.A., Kosanovich-Grek, M.L., Torgesen, J.K., Hassler, L., \& Wahl, M. (2005). Reviewing core kindergarten and first-grade reading programs in light of No Child Left Behind: An exploratory study. Reading \& Writing Quarterly (21)3777-400.

Paul, T., Swanson, S., Zhang, W., \& Hehenberger, L. (1997). Learning information system effects on reading, language arts, math, science, and social studies. (Report No. CS 013 252). Madison, WI: Institute for Academic Excellence. (ERIC Document Reproduction Service No. ED 421 686)

Patton, M.Q. (2002). Qualitative Research \& Evaluation Methods ( ${ }^{\text {rd }}$ ed.). Thousand Oaks, CA: Sage Publications.

Pavonetti, L.M., Brimmer, K.M., \& Cipielewski, J.F. (2000, November). Accelerated Reader [R]: What are the lasting effects on the reading habits of middle school students exposed to Accelerated Reader [R] in elementary grades? (Report No. CS 014 470). Paper presented at the meeting of the National Reading Conference, Scottsdale, AZ. (ERIC Document Reproduction Service No. ED 456 423) 
Peak, J., \& Dewalt, M.W. (1994, Winter). Reading achievement: Effects of computerized reading management and enrichment. ERS Spectrum, 12,(1), 31-34.

Powell-Brown, A. (2006). Why can't I just see the movie? Intervention in School and Clinic, 42(2), 84-90.

Renaissance Learning. (1992). 1992 National reading study and theory of reading practice. Madison, WI: Renaissance Learning, Inc.

Renaissance Learning. (1993). National study of literature-based reading: How literature-based reading improves both reading and math ability. Madison, WI: Renaissance Learning, Inc.

Rinehart, S.D., Gerlach, J.M., \& Wisel, D.L. (1998). Would I like to read this book?: Eighth graders' use of book cover clues to help choose recreational reading. Reading Research and Intervention, 37(4), 263-279.

Riverside Publishing. (2007). Gates-MacGinitie Reading Tests* (GMRT*) Fourth Edition Forms $S$ and T. Retrieved February 14, 2007 from http://www.riverpub.com/products/gmrt/index.html.

Rogers, L.S. (2000). The perceived impact of the Accelerated Reader Program in an elementary school. (Doctoral dissertation). Georgia Southern University.

Rosenblatt, L.M. (1994). The transactional theory of reading and writing. In R.B. Ruddell, M. R. Ruddell, \& H. Singer (Eds.), Theoretical Models and Processes of Reading ( $4^{\text {th }}$ ed.). Newark, DE: International Reading Association (pp. 1057-1089).

Schreiber, M.J. (2004). Factors affecting the efficacy of an Accelerated Reader Program: A case study. (Doctoral dissertation). Widener University. 
Sims, S.P. (2002). The effects of the Accelerated Reader Program and sustained silent reading on reading attitudes and reading achievement of eighth-grade students. (Doctoral dissertation). Georgia State University.

Smith, E.G., \& Clark, C. (2001). McKinney Independent School District (ISL): Summary of independent evaluation of districtwide Renaissance implementation. Madison, WI: School Renaissance Institute.

Standard \& Poors. SchoolMatters. Retrieved November 25, 2006 from Www.schoolmatters.com/app/compareresults

Steele, C.T. (2003). The effectiveness of the Accelerated Reader Program on the Reading Level of second-grade students as measured by the Student Test for Assessment of Reading. (Doctoral dissertation). Mississippi State University.

Stevenson, J.M., \& Camarata, J.W. (2000). Imposters in whole language clothing: Undressing the Accelerated Reader Program. Talking Points, 11(2), 2-11.

Sweet, R.W. (1996). Illiteracy: An incurable disease or education malpractice? National Right to Read Foundation.

Tompkins, G.E. (2004). Literacy for the $21^{\text {st }}$ Century ( $3^{\text {rd }}$ ed.). Upper Saddle River, NJ: Merrill Prentice Hall.

Topping, K.J., \& Fisher, A.M. (2001, February). Accelerated Reader: U.K. pilot, 1999-2000. (Report No. CS 511 430). Paper presented at the meeting of the International Reading Association World Congress on Reading, Edinburgh, Scotland. (ERIC Document Reproduction Service No. ED 468 244)

US Census Bureau (2006). State and County Quickfacts. Retreived July 6, 2006 from http://quickfacts.census.gov/qfd/index.html

Veenman, S. (1984) Perceived problems of beginning teachers. Review of Educational Research, 54(2), 143-178. 
Vollands, S.R., Topping, K.J., \& Evans, H.M. (1999). Computerized selfassessments of reading comprehension with the Accelerated Reader: Impact on reading achievement and attitude. Reading and Writing Quarterly. 15(3) 197-215.

Vygotsky, L.S. (1987). The collected works of L.S. Vygotsky: Vol. 1: Problems of general psychology. New York: Plenum.

Walker, G.A. (2005). The impact of Accelerated Reader on the reading levels of eighth-grade students at Delaware's Milford Middle School. (Doctoral dissertation). Wilmington College.

Walker, S.F. (1999a). Accelerated Reader. (Report No. CS 014 114). Denver, CO: Education Commission of the States. (ERIC Document Reproduction Service No. ED 447 420)

Walker, S.F. (1999b). Breakthrough to literacy. (Report No. CS 014 115). Denver, CO: Education Commission of the States. (ERIC Document Reproduction Service No. ED 447 421)

Walker, S.F. (1999c). Successmaker. (Report No. CS 014 130). Denver, CO: Education Commission of the States. (ERIC Document Reproduction Service No. ED 447 436)

Walker, S.F. (1999d). Waterford Early Reading Program. (Report No. CS 014 130). Denver, CO: Education Commission of the States. (ERIC Document Reproduction Service No. ED 447 438)

Watts, B.D. (2004). Accelerated Reader: Its motivational effect on advanced adolescent readers. (Master's thesis). Pacific Lutheran University.

Wigfield, A., \& McCann, A.D. (1996/1997). Children's motivations for reading, In J.L. Metsala (Ed.), The Reading Teacher, 50(4), 360-362. 


\section{APPENDIX}

\section{A: Estes Reading Attitude Scale}

$\mathrm{A}=$ strongly agree

$\mathrm{B}=$ agree

$\mathrm{C}=$ undecided

$\mathrm{D}=$ disagree

$\mathrm{E}=$ strongly disagree

1. Reading is for learning but not for enjoyment.

2. Money spent on books is well spent.

3. There is nothing to be gained from reading books.

4. Books are a bore.

5. Reading is a good way to spend spare time.

6. Sharing books in class is a waste of time.

7. Reading turns me on.

8. Reading is only for grade grubbers.

9. Books aren't usually good enough to finish.

10. Reading is rewarding to me.

11. Reading becomes boring after about an hour.

12. Most books are too long and dull.

13. Free reading doesn't teach anything.

14. There should be more time for free reading during the school day.

15. There are many books which I hope to read

16. Books should not be read except for class requirements.

17. Reading is something I can do without.

18. A certain amount of summer vacation should be set aside for reading.

19. Books make good presents.

20. Reading is dull. 


\section{B: Title Recognition Test}

Below you will see a list of book titles. Some of the titles are the names of actual books and some are not. You are to read the names and put a checkmark next to the names of those that you know are books. Do not guess, but only check those that you know are actual books. Remember, some of the titles are not those of popular books.

Adrift: 76 Days Lost at Sea

All Creatures Great and Small

BMX Champs

Beyond the Burning Time

The Boggart

Call of the Wild

Carrie

Catherine Called Birdie

Chaos in the Cafeteria

Chicken Soup for the Teenage Soul

Ella Enchanted

The Exploits of Hillary and Her Friends

Football Freaks

Frindle

The Ghosts in Room 313

Grandpa Found an Alien

Hank the Cow Dog

Hatchet

Holes

Indian in the Cupboard

Island of the Blue Dolphins

Joshua Johnson

Katie of Norway

The Legend of Sean O'Toole

Let's Save the Pandas

Melvin Meets the Moonlight Monsters

My Side of the Mountain

Mystery of the Missing Masserati

Never Lie to Your Teacher

The Outsiders

Owl in Love

Redwall

Sadie Goes to Hollywood

Searching the Wilds

The Sign of the Beaver

The Subtle Knife

The Superheroes Fan Club

To Kill a Mockingbird

Witch Baby

The Witches

Wrinkle in Time 


\section{C: Reading Interview Protacol}

Please respond to each question as fully as possible and back up your answers with examples and reasons.

1. When was the last time you read something outside of school-assigned books?

2. Did you read anything at home this week? Month? Year? Tell me about them. How did you choose them?

3. Have other people ever recommended a book to you? Have you ever recommended a book to others? Tell me about...

4. Where do you usually get the books you read?

5. Tell me about your favorite author, series, or genre.

6. What is your view of yourself as a reader? Why? What do you think it means to be a good reader?

7. What are your favorite things to read? Tell me about them.

8. What are some things that get you really excited about reading books? Tell me about...

9. Who gets you really interested and excited about reading books? Tell me more about what they do.

10. How did your reading habits change from elementary to middle school? Why?

11. How did your reading habits change since you no longer are in middle school? Why?

12. Do you remember using Accelerated Reader (AR)? Which grades?

* If Accelerated Reader was never used, stop here. If Accelerated Reader was used, continue through \#8-9. 
13. What incentives were used? How were target points set? Were there penalties for not accumulating points?

14. How did Accelerated Reader affect your reading habits when you were using it? Now that you're in high school? 


\author{
D: Introductory Letter to Parents
}

\title{
Educational Theory \& Practice
}

\section{West Virginia University}

College of Human Resources and Education

PO Box 6122

Morgantown WV 26506-6122

\section{Dear Parent/Guardian,}

I am a teacher in the local school district and am pursuing a doctoral degree through the University of West Virginia. As a part of my degree requirements, I am planning to conduct research concerning reading motivation with high school juniors under the supervision of Dr. Steven Rinehart, assistant chair/professor of Curriculum \& Instruction/Literacy Studies at WVU, who is the principal investigator of record. I am requesting your permission to allow your child to participate in a study focusing on reading motivation. Each student participating in the study will be asked to complete a reading attitude scale and a title recognition test. Additionally $10 \%$ of the participating students will be asked to provide answers in a short informal interview.

No foreseeable risks or physical discomforts are associated with this study. The data from this study will enable educators to better understand the factors involved in reading motivation. All data collected will be gathered in a confidential fashion.

For details about this study, please see the attached parent consent form.

Thank you very much.

Sincerely,

Heather Boucher 
E: Parental Consent Form

\section{PARENTAL OR GUARDI AN CONSENT AND INFORMATI ON FORM}

\section{Participation in Accelerated Reader Programs and Reading Pursuit in $11^{\text {th }}$ Grade}

\section{Introduction}

As parents/guardians of $11^{\text {th }}$ grade students at High School, you are asked to give consent for your child to participate in this research study, which will be conducted by Heather E. Boucher, a doctoral student of West Virginia University.

This research is being conducted to fulfill the requirements for a doctoral dissertation in Curriculum and Instruction in the Department of Human Resources at West Virginia University, under the supervision of Steven Rinehart, Ph.D., Assistant Chair/Professor of Curriculum and Instruction/Literacy Studies.

\section{Purposes of the Study}

The purpose of this study is to analyze the relationship between participation in a popular reading motivation program, Accelerated Reader, and reading attitudes, motivation, and pursuit. Specifically, the study will examine high school students' attitudes toward reading, their reading habits, the factors that motivate them to read, and how they choose reading materials. This study is being conducted at two high schools to specifically see if the use of the Accelerated Reader program in one school district had any impact on students' subsequent reading attitudes, motivation, and pursuit.

The regular education junior class (a minimum of 100 subjects) from two high schools are expected to be enrolled in this study; a total of at least 200 subjects are expected to participate in this study.

\section{Description of Procedures}

This study involves completing the Estes Reading Attitude Scale and circling all recognized book titles on a Title Recognition test:

The Estes Reading Attitude Scale is a method of measuring individuals' attitudes toward reading. It uses a series of twenty questions to assess both positive and 
negative reading attitudes, which are weighed on a five-point scale ranging from strongly agree to strongly disagree. The Estes Attitude Scale is estimated to take approximately 10-15 minutes.

The Title Recognition Test (TRT) is an indicator of the amount of exposure to print. In the TRT, participants are asked to mark only the titles that they recognize as books from a list of actual books interspersed with fictitious titles. There will be approximately 80 titles to consider in all. The Title Recognition Test is estimated to take approximately 10-15 minutes.

The Estes Reading Attitude Scale and the Title Recognition Test will be given to participating students by the principal investigator, Heather Boucher, at a time and location specified by the principal.

In addition to the Estes Reading Attitude Scale and the Title Recognition Test, $5 \%$ of the study's male participants and $5 \%$ of the study's female participants will be randomly chosen by sorting these assent and consent forms into piles by school and gender, and then blindly selecting the required number. The students selected in this way will be asked to give answers in an informal interview focusing on reading pursuit and motivation. The interviews will be conducted during or after school hours in a public setting agreed upon by the principal, researcher, student, and parents/guardians, such as the school library. The interviews will focus on questions concerning reading pursuit (amount/types of reading students engage in, motivating factors, book recommendations). All interviews will be audiotaped and transcribed for use in this study. It is estimated that the interviews will take between 30-60 minutes. All subjects as well as their parents or guardians will be informed of the time involved, the nature of the interview, and will have the opportunity to see the questions before they sign the consent form. They will also be made aware that they do not have to answer all of the questions and may quit the interview or entire study at any time.

\section{Risks and Discomforts}

There are no known or expected risks to your child from participating in this study, except for the mild frustration associated with answering the questions. 


\section{Alternatives}

Your child does not have to participate in this study.

\section{Benefits}

Your child may not receive any direct benefit from this study. The knowledge gained from this study may eventually benefit others.

This study will aid both school districts involved in the study gain an insight into high school students' reading motivations and pursuit in general as well as analyzing the effects of the Accelerated Reader Program.

\section{Financial Considerations}

If students are asked to volunteer their time after school to participate in the interview section of this study, they will be compensated $\$ 10$ apiece.

\section{Confidentiality}

Any information about your child that is obtained as a result of participation in this research will be kept as confidential as legally possible. Names will be withheld from all written tests, and all consent forms and data collected will be kept locked up and destroyed as soon as possible after the research is finished. Your child's research records and test results, just like hospital records, may be subpoenaed by court order or may be inspected by federal regulatory authorities without your additional consent.

In addition, there are certain instances where the researcher is legally required to give information to the appropriate authorities. These would include mandatory reporting of infectious diseases, mandatory reporting of information about behavior that is imminently dangerous to your child such as suicide, child abuse, etc.

Audiotapes of interviews will be kept locked up and will be destroyed as soon as possible after the research is finished.

In any publications that result from this research, neither your child's name nor any information from which your child might be identified will be published without your consent.

\section{Voluntary Participation}

Participation in this study is voluntary. You or your child may refuse to participate in this study. You or your child may withdraw from this study at any time. Refusal to participate or withdrawal will not affect your child's class standing or grades, and will involve no penalty to you or your child. 
In the event new information becomes available that may affect your willingness to allow your child to participate in this study, this information will be given to you so that you can make an informed decision about whether or not to continue your child's participation.

\section{Contact Persons}

In the event you have any questions about this study or experience any side effects or injury related to this research, you should contact Heather Boucher. For more information about this research and about research-related risks or injury, you can contact Heather Boucher or Dr. Steven Rinehart, Assistant Chair/Professor of Curriculum and Instruction/Literacy Studies. For information regarding your rights as a research subject, you may contact the Office of Research Compliance.

You have been given the opportunity to ask questions about the research, and have received answers concerning areas you did not understand.

Upon signing this form, you will receive a copy.

I willingly consent to allow my child to participate in this research. Signature of Parent or Guardian

Date Time Printed Name

The parent/guardian has had the opportunity to have questions addressed. The parent/guardian willingly agrees to allow his/her child to be in the study.

Investigator

Signature of Investigator or Co-

Date

Printed Name 
F: Student Assent Form

\section{ASSENT FORM}

\section{Participation in Accelerated Reader Programs and Reading Pursuit in $11^{\text {th }}$ Grade}

\section{Introduction}

As $11^{\text {th }}$ grade students, you have been asked to participate in this research study, which is being conducted by Heather E. Boucher, a doctoral student of West Virginia University.

\section{Purposes of the Study}

The purpose of this study is to learn more about high school students' attitudes toward reading, their reading habits, the factors that motivate them to read, and how they choose reading materials. This study is being conducted at two high schools to specifically see if the use of the Accelerated Reader program in one school district had any impact on students' subsequent reading attitudes, motivation, and pursuit.

\section{Description of Procedures}

This study involves completing a Reading Attitude Scale by indicating your opinion to 20 questions on a 5-point scale (ranging from strongly agree to strongly disagree) and circling all recognized book titles on a Title Recognition Test. Both measures will take approximately 20-30 minutes combined and will be given by the principal investigator, during the regular school day.

In addition, $5 \%$ of the study's male participants and $5 \%$ of the study's female participants will be randomly chosen by sorting these assent forms into piles by school and gender, and then blindly selecting the required number. The students selected in this way will be asked to give answers in an informal interview focusing on reading pursuit and motivation. The interviews will be conducted after school in a public setting agreed upon by the principal, researcher, student, and parents/guardians, such as the school library. The interviews will focus on questions concerning reading pursuit (amount/types of reading students engage in, motivating factors, book recommendations). All interviews will be audiotaped and transcribed for use in this study. It is estimated that the interviews will take between 30-60 minutes. All subjects as well as their parents or guardians will be informed of the time involved, the nature of the interview, and will have the opportunity to see the questions before they sign the consent form. They will also be made aware that they do not have to answer all of the questions and may quit the interview or entire study at any time.

\section{Discomforts}

Some of the questions will be difficult and you may not enjoy trying to answer them.

\section{Benefits}

This study may not help you, but what educators learn from the study may help other people. 


\section{Financial Considerations}

If you are one of the randomly chosen students who volunteer their time after school to participate in the interview section of this study, you will be compensated $\$ 10$.

\section{Confidentiality}

We promise that anything we learn about you in this study will be kept as secret as possible.

\section{Voluntary Participation}

You do not have to do this. No one will be mad at you if you refuse to do this or if you decide to quit.

\section{Contact Persons}

In the event you have any questions about this study or experience any side effects or injury related to this research, you should contact Heather Boucher. For more information about this research and about research-related risks or injury, you can contact Heather Boucher or Dr. Steven Rinehart, Assistant Chair/Professor of Curriculum and Instruction/Literacy Studies. For information regarding your rights as a research subject, you may contact the Office of Research Compliance.

You have been allowed to ask questions about the research, and all of your questions were answered.

I willingly agree to be in this research.

Date

The student has had the opportunity to have questions addressed. The student willingly agrees to be in the study. Signature of Investigator or Co-Investigator Printed Name

Date




\section{G: Trends Noted from the Interviews}

\begin{tabular}{|c|c|c|c|}
\hline & & School A & School B \\
\hline \multirow[t]{5}{*}{ The last time they read something } & Last night & $2 \mathrm{~m} \mathrm{1f}$ & $3 \mathrm{f}$ \\
\hline & Last week & & $2 \mathrm{~m}$ \\
\hline & Last month & $2 \mathrm{~m} 4 \mathrm{f}$ & $2 \mathrm{~m}$ \\
\hline & Last summer & $1 \mathrm{~m} 1 \mathrm{f}$ & $1 \mathrm{~m}$ \\
\hline & More than 1 year & & $2 \mathrm{f}$ \\
\hline \multirow{6}{*}{$\begin{array}{l}\text { Why so long (asked if it was more } \\
\text { than a week since the student read } \\
\text { anything outside of school books) }\end{array}$} & Schoolwork & $1 \mathrm{~m} 3 \mathrm{f}$ & $1 \mathrm{~m} 3 \mathrm{f}$ \\
\hline & Sports & $2 \mathrm{~m} 1 \mathrm{f}$ & $1 \mathrm{f}$ \\
\hline & Other Activities & & \\
\hline & Work & $1 \mathrm{~m}$ & $2 \mathrm{f}$ \\
\hline & Don't like to read & & $1 \mathrm{f}$ \\
\hline & Only like 1 series & $1 \mathrm{f}$ & \\
\hline \multirow[t]{7}{*}{ Where books are acquired } & Bookstores & $3 \mathrm{~m} \mathrm{3f}$ & $4 \mathrm{~m} 2 \mathrm{f}$ \\
\hline & Friends & $1 \mathrm{f}$ & $2 \mathrm{~m}$ \\
\hline & Home/Family & $2 \mathrm{~m} 1 \mathrm{f}$ & $2 \mathrm{f}$ \\
\hline & Library & $2 \mathrm{f} 2 \mathrm{~m}$ & $1 \mathrm{~m} 2 \mathrm{f}$ \\
\hline & School & $1 \mathrm{f}$ & \\
\hline & Youth Group & $1 \mathrm{f}$ & \\
\hline & Book Fairs & & $1 \mathrm{f}$ \\
\hline \multirow[t]{4}{*}{ Who recommends books to them } & Friends & $3 \mathrm{~m} 1 \mathrm{f}$ & $3 \mathrm{~m}$ \\
\hline & Family & $5 \mathrm{~m} 4 \mathrm{f}$ & $1 \mathrm{~m} 4 \mathrm{f}$ \\
\hline & Teachers & $2 \mathrm{~m}$ & \\
\hline & Self & & \\
\hline \multirow{4}{*}{$\begin{array}{l}\text { Who gets them excited about } \\
\text { reading }\end{array}$} & Friends & $1 \mathrm{~m} 2 \mathrm{f}$ & $2 \mathrm{~m} 1 \mathrm{f}$ \\
\hline & Family & $3 \mathrm{~m} \mathrm{3f}$ & $2 \mathrm{~m} 4 \mathrm{f}$ \\
\hline & Teachers & $2 \mathrm{f}$ & $1 \mathrm{~m} 2 \mathrm{f}$ \\
\hline & Self & $1 \mathrm{f}$ & $1 \mathrm{~m}$ \\
\hline \multirow{7}{*}{$\begin{array}{l}\text { What gets them excited about } \\
\text { reading }\end{array}$} & Learning & & $3 \mathrm{~m} \mathrm{3f}$ \\
\hline & Enjoyment & $1 \mathrm{~m} 3 \mathrm{f}$ & $2 \mathrm{~m} 1 \mathrm{f}$ \\
\hline & Rewards & $1 \mathrm{~m}$ & \\
\hline & Book-it & $1 \mathrm{~m}$ & $1 \mathrm{f}$ \\
\hline & AR Prizes & $1 \mathrm{~m} \mathrm{1 \textrm {f }}$ & \\
\hline & Pictures/Book Covers & $1 \mathrm{f}$ & $3 \mathrm{f}$ \\
\hline & Book reports & $1 \mathrm{~m}$ & \\
\hline \multirow[t]{8}{*}{ View of self as a reader } & High & $2 \mathrm{~m} \mathrm{1f}$ & $1 \mathrm{f}$ \\
\hline & Average & $1 \mathrm{~m} 2 \mathrm{f}$ & $1 \mathrm{f}$ \\
\hline & Low & $1 \mathrm{f}$ & $1 \mathrm{f}$ \\
\hline & Read little & $2 \mathrm{f}$ & $4 \mathrm{~m}$ \\
\hline & Read a lot & $1 \mathrm{~m}$ & $1 \mathrm{f}$ \\
\hline & Enjoy reading & $2 \mathrm{f}$ & $1 \mathrm{~m}$ \\
\hline & Read for fun & & $1 \mathrm{~m}$ \\
\hline & Reading level & $3 \mathrm{f} 1 \mathrm{~m}$ & \\
\hline \multirow{4}{*}{\multicolumn{2}{|c|}{ Favorite author }} & J.K. Rowling $1 \mathrm{~m}$ & J.K. Rowling $1 \mathrm{~m} 1 \mathrm{f}$ \\
\hline & & Mark Batterson $1 \mathrm{f}$ & James Patterson $1 \mathrm{~m}$ \\
\hline & & Madeline L'Engle $1 \mathrm{~m}$ & Nicholas Sparks $1 \mathrm{f}$ \\
\hline & & Steven King $1 \mathrm{~m}$ & Barbara Park* 1 f \\
\hline \multirow{2}{*}{\multicolumn{2}{|c|}{ Favorite series }} & Harry Potter $2 \mathrm{~m} 1 \mathrm{f}$ & Harry Potter $1 \mathrm{~m} 2 \mathrm{f}$ \\
\hline & & Twilight $1 \mathrm{~m} 1 \mathrm{f}$ & Junie B. Jones* $1 \mathrm{f}$ \\
\hline \multirow{2}{*}{\multicolumn{2}{|c|}{ *In earlier grades. }} & Sword of Truth $1 \mathrm{~m}$ & \\
\hline & & Hank the Cow Dog*: $1 \mathrm{~m}$ & \\
\hline \multirow[t]{11}{*}{ Favorite genre } & & Romance $1 \mathrm{~m} 2 \mathrm{f}$ & Romance $1 \mathrm{~m}$ \\
\hline & & Mystery $2 \mathrm{f}$ & Mystery $1 \mathrm{f} 1 \mathrm{~m}$ \\
\hline & & Science Fiction $4 \mathrm{~m}$ & Adventure $1 \mathrm{~m}$ \\
\hline & & Autobiographies $1 \mathrm{f}$ & Textbooks/Encyclopedias $1 \mathrm{~m}$ \\
\hline & & Fantasy $2 \mathrm{~m} 2 \mathrm{f}$ & World Records $1 \mathrm{~m}$ \\
\hline & & History/Science $1 \mathrm{~m}$ & Political/Science $2 \mathrm{~m}$ \\
\hline & & Teenage $2 \mathrm{f}$ & \\
\hline & & Psychology $1 \mathrm{f}$ & Psychoanalysis $1 \mathrm{f}$ \\
\hline & & The Classics $1 \mathrm{f}$ & \\
\hline & & Comedy $1 \mathrm{f}$ & \\
\hline & & Inspirational books $1 \mathrm{f}$ & \\
\hline
\end{tabular}




\begin{tabular}{|c|c|c|c|}
\hline & & School A & School B \\
\hline \multirow[t]{8}{*}{$\begin{array}{l}\text { How reading habits changed from } \\
\text { elementary to middle school }\end{array}$} & $\begin{array}{l}\text { Read more in middle } \\
\text { school }\end{array}$ & $1 \mathrm{f}$ & $1 \mathrm{~m} 4 \mathrm{f}$ \\
\hline & $\begin{array}{l}\text { Read less in middle } \\
\text { school }\end{array}$ & $1 \mathrm{~m} 2 \mathrm{f}$ & $1 \mathrm{~m}$ \\
\hline & $\begin{array}{l}\text { Read the same } \\
\text { amount }\end{array}$ & $1 \mathrm{f}$ & $1 \mathrm{~m} 1 \mathrm{f}$ \\
\hline & $\begin{array}{l}\text { Read more complex } \\
\text { books }\end{array}$ & $2 \mathrm{~m} 1 \mathrm{f}$ & $2 \mathrm{~m} 2 \mathrm{f}$ \\
\hline & $\begin{array}{l}\text { Started to enjoy } \\
\text { reading }\end{array}$ & $1 \mathrm{~m}$ & \\
\hline & Read better & $1 \mathrm{~m}$ & $1 \mathrm{f}$ \\
\hline & Read faster & $1 \mathrm{f}$ & \\
\hline & $\begin{array}{l}\text { Just learning to read } \\
\text { in English }\end{array}$ & $1 \mathrm{f}$ & \\
\hline \multirow[t]{8}{*}{$\begin{array}{l}\text { How reading habits changed from } \\
\text { middle school to high school }\end{array}$} & $\begin{array}{l}\text { Read more in high } \\
\text { school }\end{array}$ & $1 \mathrm{f}$ & $5 \mathrm{~m} 2 \mathrm{f}$ \\
\hline & $\begin{array}{l}\text { Read less in high } \\
\text { school }\end{array}$ & $3 \mathrm{~m} 3 \mathrm{f}$ & $3 \mathrm{f}$ \\
\hline & $\begin{array}{l}\text { Read the same } \\
\text { amount }\end{array}$ & & $1 \mathrm{f}$ \\
\hline & $\begin{array}{l}\text { Read more complex } \\
\text { books }\end{array}$ & $2 \mathrm{~m} 1 \mathrm{f}$ & $2 \mathrm{~m}$ \\
\hline & $\begin{array}{l}\text { Discovered a new } \\
\text { favorite genre }\end{array}$ & $1 \mathrm{f}$ & \\
\hline & $\begin{array}{l}\text { Reading is more } \\
\text { interesting }\end{array}$ & & $1 \mathrm{~m} 1 \mathrm{f}$ \\
\hline & Read better & $1 \mathrm{~m}$ & \\
\hline & Not as much time & & $1 \mathrm{~m} 1 \mathrm{f}$ \\
\hline
\end{tabular}

$\mathrm{m}=$ male; $\mathrm{f}=$ female 